\title{
Morphological disparity and systematic revision of the eocrinoid genus Rhopalocystis (Echinodermata, Blastozoa) from the Lower Ordovician of the central Anti-Atlas (Morocco)
}

\author{
Ninon Allaire, ${ }^{1,2}$ Bertrand Lefebvre, ${ }^{2}$ Elise Nardin, ${ }^{3}$ Emmanuel L.O. Martin, ${ }^{2}$ Romain Vaucher, ${ }^{2}$ and \\ Gilles Escarguel ${ }^{4}$ \\ ${ }^{1}$ Université de Lille, CNRS, UMR 8198 Evo-Eco-Paleo, F-59000 Lille, France〈ninon.allaire@ univ-lille1.fr〉 \\ ${ }^{2}$ Université Claude Bernard Lyon 1, ENS de Lyon, CNRS, UMR 5276 LGL-TPE, F-69622 Villeurbanne, France \\ 〈bertrand.lefebvre@univ-lyon1.fr〉,〈emmanuel.martin@univ-lyon1.fr〉,〈romain.vaucher@univ-lyon1.fr \\ ${ }^{3}$ Géosciences Environnement Toulouse, Observatoire Midi-Pyrénées, CNRS/UPS/IRD, 14 avenue Edouard Belin, 31400 Toulouse, France \\ 〈elise.nardin@get.omp.eu〉 \\ ${ }^{4}$ Université Claude Bernard Lyon 1, CNRS, ENTPE, UMR 5023 LEHNA, F-69622 Villeurbanne, France〈gilles.escarguel@univ-lyon1.fr〉
}

\begin{abstract}
The genus Rhopalocystis (Eocrinoidea, Blastozoa) is characterized by both a short stratigraphic range (Fezouata Shale, middle Tremadocian to middle Floian, Lower Ordovician) and a reduced geographic extension (Agdz-Zagora area, central Anti-Atlas, Morocco). Since the original description of its type species $(R$. destombesi Ubaghs, 1963), three successive revisions of the genus Rhopalocystis have led to the erection of nine additional species. The morphological disparity within this genus is here critically reassessed on the basis of both historical material and new recently collected samples. The detailed examination of all specimens, coupled with morphometric and cladistic analyses, points toward a relatively strong support for five morphotypes. A systematic revision of Rhopalocystis is thus suggested, with only five valid taxa: $R$. destombesi, $R$. fraga Chauvel, 1971, $R$. grandis Chauvel, 1971, R. havliceki Chauvel, 1978, and R. zagoraensis Chauvel, 1971. The five others are considered as junior synonyms $(R$. dehirensis Chauvel and Régnault, 1986, $R$. lehmani Chauvel and Régnault, 1986, $R$. sp. A, $R$. sp. B, and $R$. sp. C).
\end{abstract}

\section{Introduction}

In the Lower Ordovician sequence of the Zagora area (central Anti-Atlas, southern Morocco), echinoderms are one of the major components of benthic faunas (Lefebvre et al., 2016b). In recent years, the Fezouata Shale Formation (Tremadocian to Floian) has yielded numerous exquisitely preserved echinoderm assemblages (or echinoderm Lagerstätten sensu Smith, 1988), which document the early stages of the Great Ordovician Biodiversification Event (Noailles et al., 2010; Lefebvre et al., 2016b).

The eocrinoid genus Rhopalocystis Ubaghs, 1963 is one of the most common echinoderm taxa in the Lower Ordovician of the central Anti-Atlas. Its morphology is characterized by a mixture of plesiomorphic (e.g., epispires) and more advanced characters (e.g., theca organized into well-defined circlets of plates). The phylogenetic position of Rhopalocystis remains largely unresolved. It was identified as a gogiid eocrinoid (Sprinkle, 1973; Broadhead, 1982), assigned to various groups of more derived blastozoans (e.g., Paul, 1988; Sumrall et al., 2001; Nardin, 2007), or interpreted as a possible transitional form between blastozoans and crinoids (e.g., Ausich et al., 2013, 2015; but see Ubaghs, 1963; Guensburg and Sprinkle, 2007; Guensburg et al., 2016). Isolated skeletal remains from the Valdemiedes Formation (Cambrian Series 2, Stage 4) of
Spain were tentatively assigned to Rhopalocystis (Clausen, 2004). However, they more likely belong to a yet undescribed gogiid eocrinoid (personal communication, S. Zamora, 2013).

The stratigraphic and paleobiogeographic distribution of Rhopalocystis are so far restricted to the Lower Ordovician (middle Tremadocian to middle Floian) of the Agdz-Zagora area (central Anti-Atlas, Morocco; Allaire et al., 2015; Lefebvre et al., 2016b). In the past 50 years, these levels have yielded hundreds of remarkably well-preserved specimens (Ubaghs, 1963; Chauvel, 1971, 1978; Chauvel and Régnault, 1986; Allaire et al., 2015; Lefebvre et al., 2016b).

The genus Rhopalocystis was originally described on the basis of abundant material collected by J. Destombes on the eastern flank of Jbel Bou Dehir (locality 1157; Fig. 1). All individuals were assigned to the type species, $R$. destombesi Ubaghs, 1963 (Fig. 2). Thanks to the remarkable preservation of the material and the large number of available samples, Ubaghs (1963) made a particularly detailed study of its general morphology. In $R$. destombesi, the aboral part of the theca is composed of eleven plates arranged into three circlets: one single basal, four infralaterals, and six laterals (Fig. 2.1). The upper part of the theca comprises five perradial areas (each consisting of a column of four radials) and five interradial areas (each composed of a higher number of plates arranged in four to 

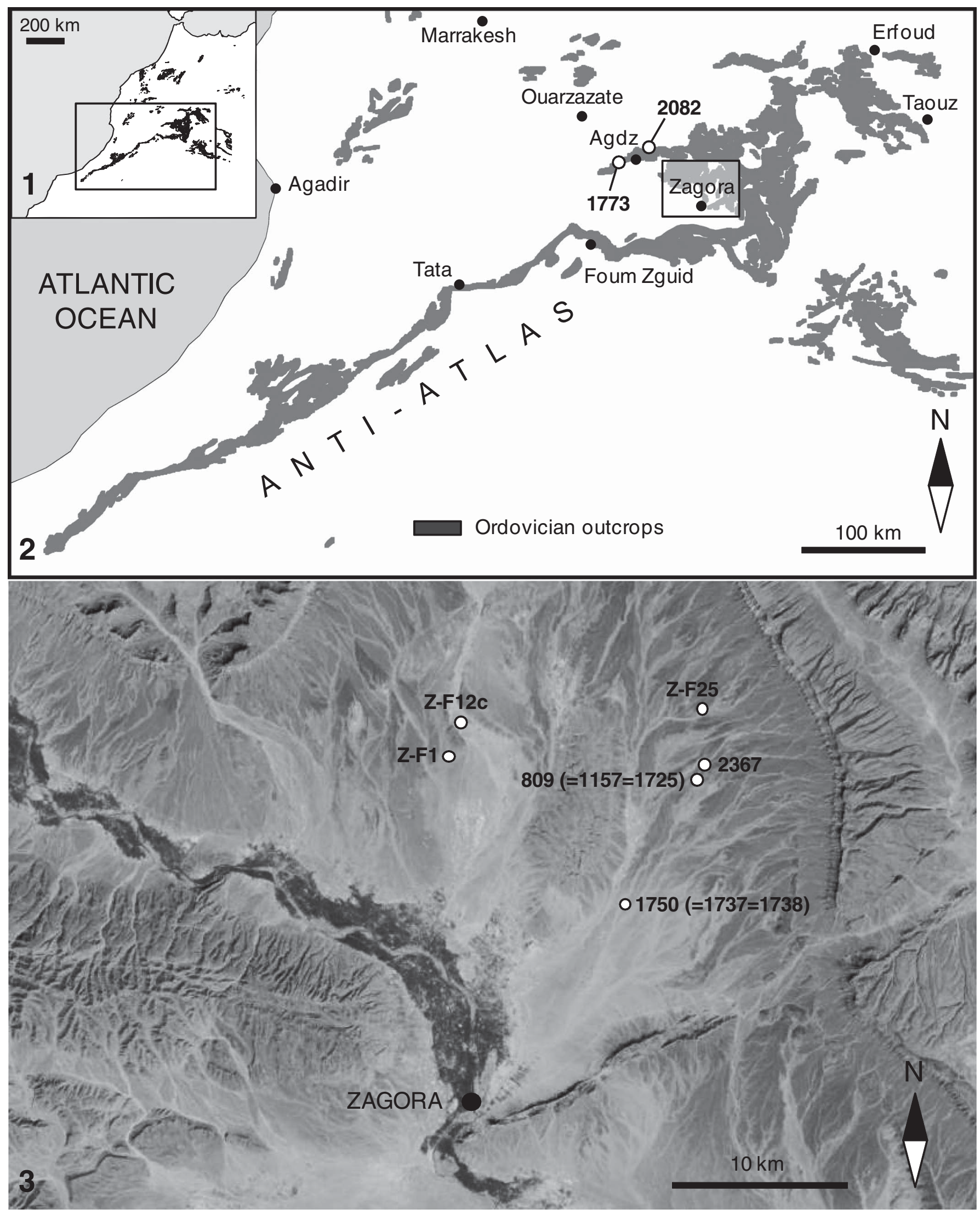

Figure 1. Locality maps of the Rhopalocystis sites (modified after Lefebvre et al., 2016b). (1) Location of the Anti-Atlas range in northwestern Africa. (2) Simplified geological map of the Anti-Atlas showing the Ordovician outcrops and the location of the Zagora area and of localities 1773 and 2082 (Agdz area, Destombes localities). (3) Landsat view (Google Earth 2016) of the Zagora area showing the location sites $809(=1157=1725), 1750(=1737=1738), 2367$ (Destombes localities); Z-F1, Z-F12c, and Z-F25 (new localities recently discovered). 
five successive rows). The anal cone (and associated periproct) is located within the CD interradial area (Fig. 2.2).

The collection of abundant material from several new sites discovered by J. Destombes in Tremadocian levels around Agdz and Zagora led Chauvel (1971) to revise the genus Rhopalocystis and to identify four new species: $R$. fraga Chauvel, 1971, $R$. grandis Chauvel, 1971, $R$. zagoraensis Chauvel, 1971, and $R$. sp. A. The first one, R. fraga (locality 1773; Fig. 1), has a small strawberry-shaped theca, with its aboral-most elements (basal, infralaterals) characterized by a particularly stocky appearance. The second species, $R$. grandis (locality $1725=1157$; Fig. 1) possesses a very large theca, composed of numerous irregular plates, which are covered with small granulations. The third species, $R$. zagoraensis (locality $809=$ $1725=1157$; Fig. 1), is comparable in size to $R$. destombesi but differs from it by the presence of numerous plates intercalated both between the infralateral and lateral circlets and between the lateral and radial circlets, and a strong ornamentation (vermiculate radiating ridges). Finally, several specimens from locality 1738 $(=1737=1750 ;$ Fig. 1$)$ were left in open nomenclature $(R$. sp. A). Although their morphology appeared to be distinct from that of other species of Rhopalocystis, their poor preservation prevented Chauvel (1971) from describing them accurately and from assigning them to a new taxon.

Additional new material collected by J. Destombes in the central Anti-Atlas prompted the revision of $R$. zagoraensis and the description of three additional taxa by Chauvel (1978). The first one, R. havliceki Chauvel, 1978 (localities $1725=1157$, 2082; Fig. 1) corresponds to large individuals with numerous lateral plates. This species was mostly defined by its ornamentation: radials are spine-shaped and infralaterals bear a rounded protuberance (umbo). The two other taxa were left in open nomenclature ( $R$. sp. B and $R$. sp. C) due to the poor preservation of the material. Rhopalocystis sp. B (locality $1738=1737=1750$; Fig. 1) was defined on the basis of several internal molds of poorly preserved thecae showing similarities with both $R$. fraga and $R$. destombesi. Rhopalocystis sp. C (locality 2082; Fig. 1) was described from a very incomplete portion of theca (with both its aboral and adoral extremities missing). Several plates of this fragmentary theca show a strong ornamentation consisting of particularly robust, spine-shaped protuberances.

Finally, additional material collected by J. Destombes (locality 2367; Fig. 1) led Chauvel and Régnault (1986) to revise the genus Rhopalocystis and to identify two new species, which they considered as morphologically intermediate between $R$. destombesi and $R$. zagoraensis. In the scheme defined by Chauvel and Régnault (1986), specimens with one or several intercalary plates (forming an incomplete circlet) inserted between infralaterals and laterals, and/or between laterals and radials, were attributed to $R$. destombesi. Individuals with a complete circlet of intercalary plates between infralaterals and laterals were assigned to $R$. dehirensis Chauvel and Régnault, 1986. Those with more than one circlet of intercalary plates inserted between infralaterals and laterals were identified as R. lehmani Chauvel and Régnault, 1986. Both R. dehirensis and $R$. lehmani could also have additional plates between laterals and radials. Finally, Chauvel and Régnault (1986) suggested that all specimens with three regular circlets of intercalary plates between infralaterals and laterals and one circlet between laterals and radials should be attributed to $R$. zagoraensis.

The taxonomy and morphological disparity of Rhopalocystis have not been reinvestigated since Chauvel and Régnault (1986). As a result of the successive systematic descriptions produced by Ubaghs (1963), Chauvel (1971, 1978), and Chauvel and Régnault (1986), the genus Rhopalocystis now includes ten species: $R$. dehirensis, $R$. destombesi, $R$. fraga, $R$. grandis, $R$. havliceki, $R$. lehmani, $R$. zagoraensis, $R$. sp. A, $R$. sp. B, and $R$. sp. C. However, as already pointed out by several authors (e.g., Smith, 1988; Lefebvre et al., 2016b), it is very likely that this high intrageneric taxonomic diversity is largely overestimated and at least partly reflects ecophenotypy and/or wide morphological disparity. In recent years, abundant new material of Rhopalocystis was collected from three new localities in Zagora area (Z-F1, Z-F12c, Z-F25; Fig. 1). Therefore, the aim of this study is to analyze the morphological disparity of Rhopalocystis and to propose a critical reassessment of its systematics based on abundant material available in the historical Destombes collections and the newly collected specimens.

\section{Geological setting}

In the Agdz-Zagora area, the Lower Ordovician succession corresponds to a thick $(\sim 1,000 \mathrm{~m})$, relatively monotonous series of claystones and fine siltstones (Lefebvre et al., 2016a; Martin et al., 2016; Vaucher et al., 2016), which is traditionally subdivided into three successive stratigraphic units: the Lower Fezouata Formation, the Upper Fezouata Formation, and the Zini Sandstone Formation (Destombes, 1962, 1971; Destombes et al., 1985; Vidal, 1996). However, in the central part of the Anti-Atlas, the two lower units cannot be distinguished, and they form together the Fezouata Shale (Tremadocian to Floian) (Lefebvre et al., 2016a; Martin et al., 2016). In both areas, the different sedimentary facies observed in this succession range from proximal offshore to distal lower shoreface and illustrate a sedimentary system dominated by the swell, strongly influenced by storms but modulated by tides (Vaucher et al., 2017).

In the past twelve years, successive field excursions in the Ternata plain (north of Zagora) resulted in the detailed logging of the whole Lower Ordovician succession and in the definition of a precise biostratigraphic framework based on abundant new collections of acritarchs and chitinozoans (Nowak et al., 2016), conodonts (Lehnert et al., 2016), and graptolites (GutiérrezMarco and Martin, 2016; Martin et al., 2016). During this recent field work, three new sites yielding abundant remains of Rhopalocystis (localities Z-F1, Z-F12c, Z-F25; Fig. 1) were discovered (Allaire et al., 2015). All Rhopalocystis-bearing strata are located in the Fezouata Shale of the Agdz-Zagora area: most of them occur within the Ternata plain (Destombes localities $1157=1725, \quad 1737=1738=1750,2367$; new localities Z-F1, Z-F12c, Z-F25; Fig. 1); two sites are located around Agdz (Destombes localities 1773, 2082; Fig. 1). The resulting biostratigraphic reassignment of Rhopalocystisbearing localities suggests a wider stratigraphic range for this genus (Fig. 3), from the middle Tremadocian (A. victoriae Zone) to the middle Floian (?B. jacksoni Zone) (Lefebvre et al., 2016b).

In the Agdz-Zagora area, the first $240 \mathrm{~m}$ of the Fezouata Shale (early to middle Tremadocian, A. matanensis to 

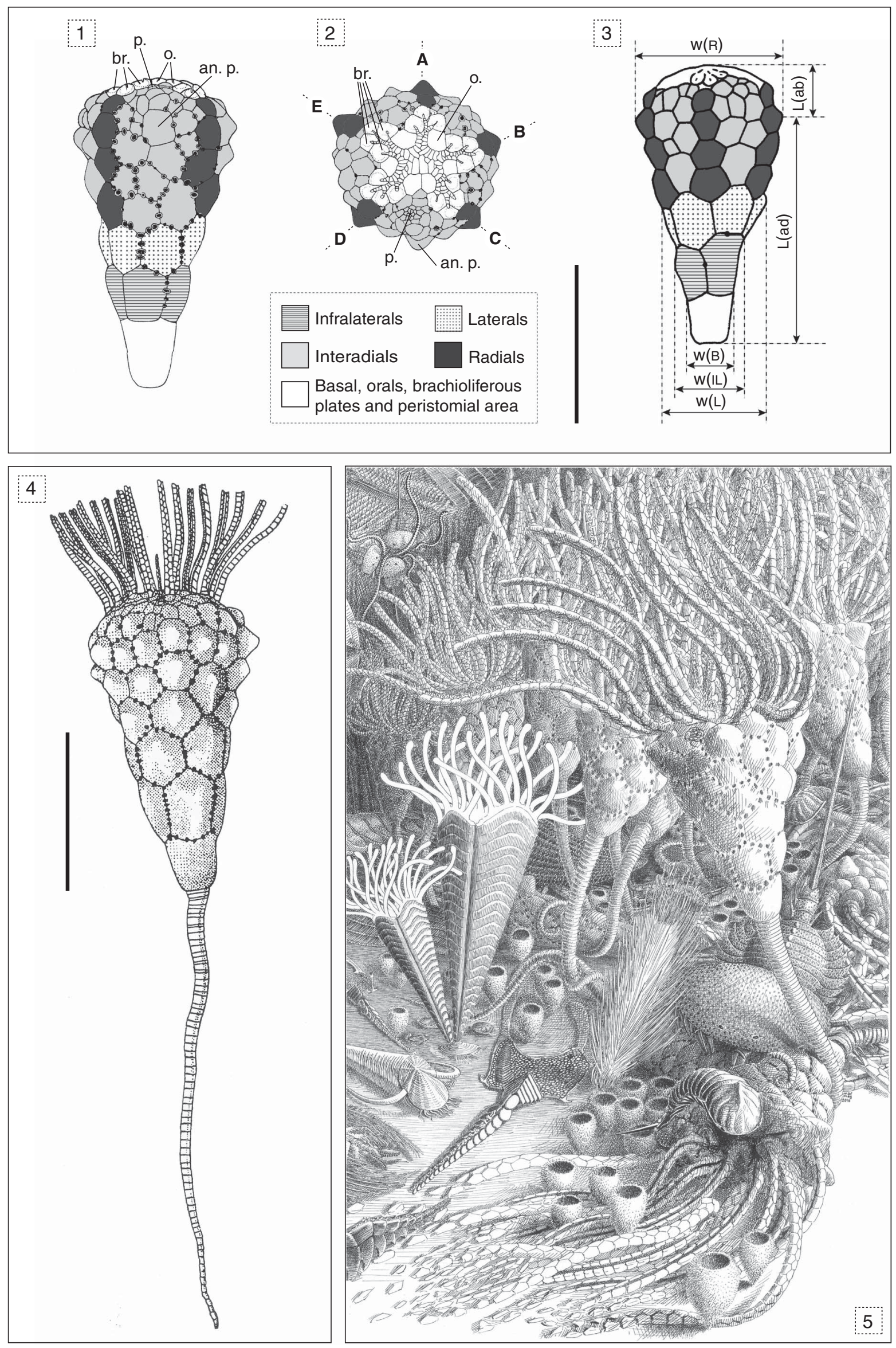
A. victoriae graptolite Zones) yielded extremely few remains of marine invertebrates (rare specimens of inarticulate brachiopods, trilobites, and graptolites), with the remarkable exception of locally abundant accumulations of fully articulated thecae of Rhopalocystis (Fig. 3, locality $1737=1738=1750$, A. victoriae Zone, middle Tremadocian; Destombes, 2006; Allaire et al., 2015; Lefebvre et al., 2016b). In the Fezouata Shale, the most abundant and diverse echinoderm faunas, including several Rhopalocystis assemblages (Fig. 3, localities $809=1157=1725, \mathrm{Z}-\mathrm{F} 1, \mathrm{Z}-\mathrm{F} 12 \mathrm{c}$ ), were recorded within the A. murrayi Zone (late Tremadocian; Allaire et al., 2015; Lefebvre et al., 2016b). The last two localities (Fig. 3; 2367, Z-F25) yielding Rhopalocystis assemblages are respectively attributed to the $H$. copiosus Zone (late Tremadocian) and the ?B. jacksoni Zone (middle Floian), (Lefebvre et al., 2016b).

\section{Taphonomy and paleoecology}

Two main types of preservation are described for the different Rhopalocystis-dominated assemblages (Ubaghs, 1963; Allaire et al., 2015). The first kind of preservation (e.g., localities 2367, Z-F12c, Z-F25; Fig. 4.1, 4.2, 4.5) corresponds to extremely dense accumulations of Rhopalocystis (fully articulated thecae) in storm-generated, massive sandstone lenses (Allaire et al., 2015; Lefebvre et al., 2016b). Fragmented stems are sometimes preserved, either isolated or articulated to the thecae. Brachioles are usually missing. This first taphofacies can be interpreted as storm-generated Konzentrat-Lagerstätten (Vaucher et al., 2016), resulting from the downslope transport and accumulation of allochthonous Rhopalocystis-dominated communities. These Konzentrat-Lagerstätten suggest the persistence of Rhopalocystis-dominated eocrinoid meadows in shallower and high-energy environmental conditions, from the middle Tremadocian (A. victoriae Zone) to the middle Floian (?B. jacksoni Zone), in the Ternata plain (Lefebvre et al., 2016b; Vaucher et al., 2016).

The second type of Rhopalocystis-dominated assemblage (e.g., localities 1773, Z-F1, Fig. 4.3, 4.4, 4.6) is restricted to the lower part of the A. murrayi Zone. It corresponds to low-density accumulations of exquisitely preserved specimens of Rhopalocystis conserved in fine laminated siltstones (Allaire et al., 2015). Most of them are moderately disarticulated, and some thecal plates are frequently slightly displaced or collapsed. Large portions of stems are often preserved articulated to the theca. Brachioles are seldom present (Ubaghs, 1963; Allaire et al., 2015). These assemblages can be interpreted as Konservat-Lagerstätten
(Vaucher et al., 2016), resulting from the in situ burial of Rhopalocystis communities by distal storm events.

The Rhopalocystis-dominated communities could have occupied both proximal environments with high-energy conditions (e.g., localities Z-F12c, Z-F25) and more distal environments associated with lower energy conditions (e.g., locality Z-F1) (Allaire et al., 2015; Lefebvre et al., 2016b). The stem of Rhopalocystis seems to be long and flexible with no attachment structure (Fig. 2.4). Therefore, individuals could possibly attach the distal extremity of their stem by winding it around other organisms (Fig. 2.5), allowing them to maintain their position in relatively high-energy environmental conditions.

\section{Materials and methods}

Sample preparation.-Because all individuals are preserved as imprints of external molds, latex casts were made and whitened with ammonium chloride $\left(\mathrm{NH}_{4} \mathrm{Cl}\right)$, to be observed and drawn under a stereomicroscope with a camera lucida. The specimens were photographed with a Nikon D3X camera (objective Macronikkor $60 \mathrm{~mm}$ ) under raking light and with the camera (Leica DCI) of the stereomicroscope. The best-preserved thecae were selected (58 specimens) to perform the cladistic and morphometric analyses.

Cladistic analysis.-Nine thecal multistate characters (e.g., ornamentation, plate shape, number of plate circlets, supplementary plates) were investigated through a cladistic analysis to characterize maximally parsimonious clusters, that is, groups of specimens that minimize within-group interspecimen variability with respect to between-group interspecimen morphological variability (Table 1; Fig. 5). The different states of these characters were determined for the 58 selected individuals. The thecal length was measured and discretized into two classes determined by a finite Gaussian mixture model and its Akaike information criterion (Akaike, 1974; Dempster et al., 1977). The inferred cutoff value obtained was $4.74 \mathrm{~cm}$. Consequently, the character state 'small' was assigned to the specimens with a thecal length less than $4.74 \mathrm{~cm}$; the character state 'large' was assigned to those with a thecal length equal to or greater than $4.74 \mathrm{~cm}$.

Rather than a distance-based phenetic (cluster) analysis, a cladistic analysis was performed here using Wagner parsimony on unordered multistate characters as implemented in the PARS software from the PHYLIP 3.67 $\alpha 3$ package (Felsenstein et al., 2005). Among other considerations, this choice was strongly motivated by the presence of missing values in the

\footnotetext{
Figure 2. Rhopalocystis destombesi Ubaghs, 1963. (1, 2) Morphological features of R. destombesi, holotype (A29134 and A29120, part and counterpart); drawings modified from Ubaghs (1963, text-fig. 2.2, 2.3); locality 809 (=1157=1725), late Tremadocian (A. murrayi Zone). (1) Theca showing the posterior interradial area (between the radius $\mathrm{C}$ and $\mathrm{D}$ ), which contains the anal protuberances and the periproct. (2) Oral surface of the theca showing the five ambulacra (each consisted of four brachioliferous plates), the oral plates $(\mathrm{six})$, and the peristomial area covered with very small plates. p. $=$ periproct; an. p. $=$ anal protuberance; br. $=$ brachioliferous plates; o. $=$ oral plates. (3) Presentation of the six variables used in the morphometric analysis, $R$. destombesi (ML 20.269.380a). L $(\mathrm{ab})=$ aboral thecal length; $\mathrm{L}(\mathrm{ad})=$ adoral thecal length; $\mathrm{W}(\mathrm{B})=$ basal width; W(IL) $=$ infralateral width; W(L) = lateral width; $\mathrm{W}(\mathrm{R})=$ radial width. (4) Reconstitution of $R$. destombesi, based on the holotype (A29134 and A29120) and on a specimen coming from the sample A29122; drawing modified from Ubaghs $(1963$, text-fig. 1$)$; locality $809(=1157=1725)$, late Tremadocian $($ A. murrayi Zone). The theca is shown in anterior aspect (radius A); the brachioles are not entirely represented; the small brachiole located on the ambulacra A is considered in development. (5) Artistic reconstruction of a Rhopalocystis destombesi meadow, with other typical organisms of the Fezouata Shale (Lower Ordovician, central Anti-Atlas, Morocco): conulariids (Eoconularia sp.), demosponges (Pirania auraeum and Hamptonia christi), stylophorans (Thoralicystis sp.), hyolithids (Elegantilites sp.), and arthropods (xiphosurid and basal chelicerate). The stem of Rhopalocystis seemed to be flexible; they could probably be attached by winding it around sufficiently solid elements. Illustration by mad meg. Scale bars $=1 \mathrm{~cm}$.
} 


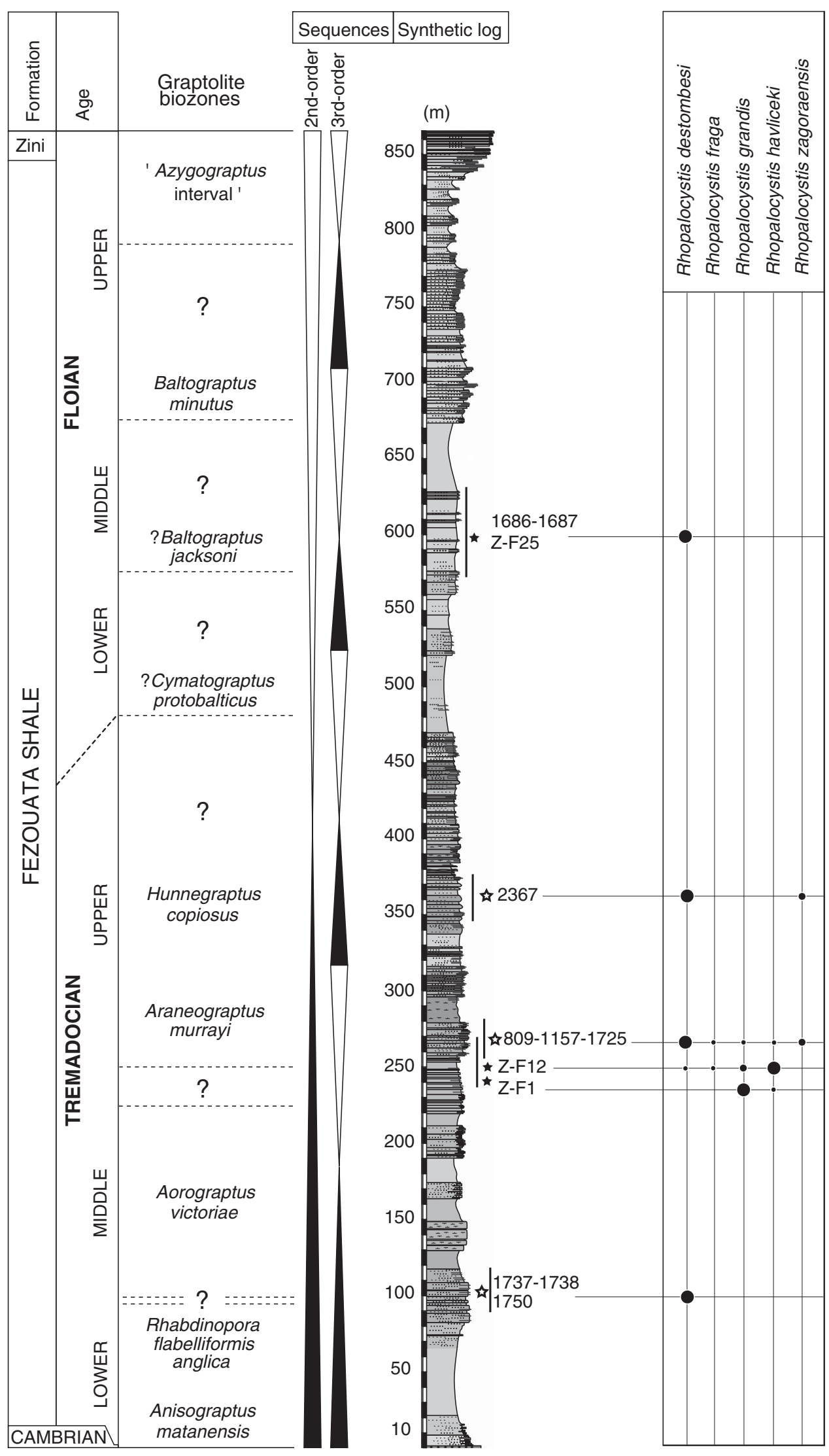

$\begin{array}{lll}\text { Relative abundance: } & \text { - } & \text { care } \\ & \text { common } \\ & \text { abundant }\end{array}$

Samples: J. Destombes

$\star$ This study 


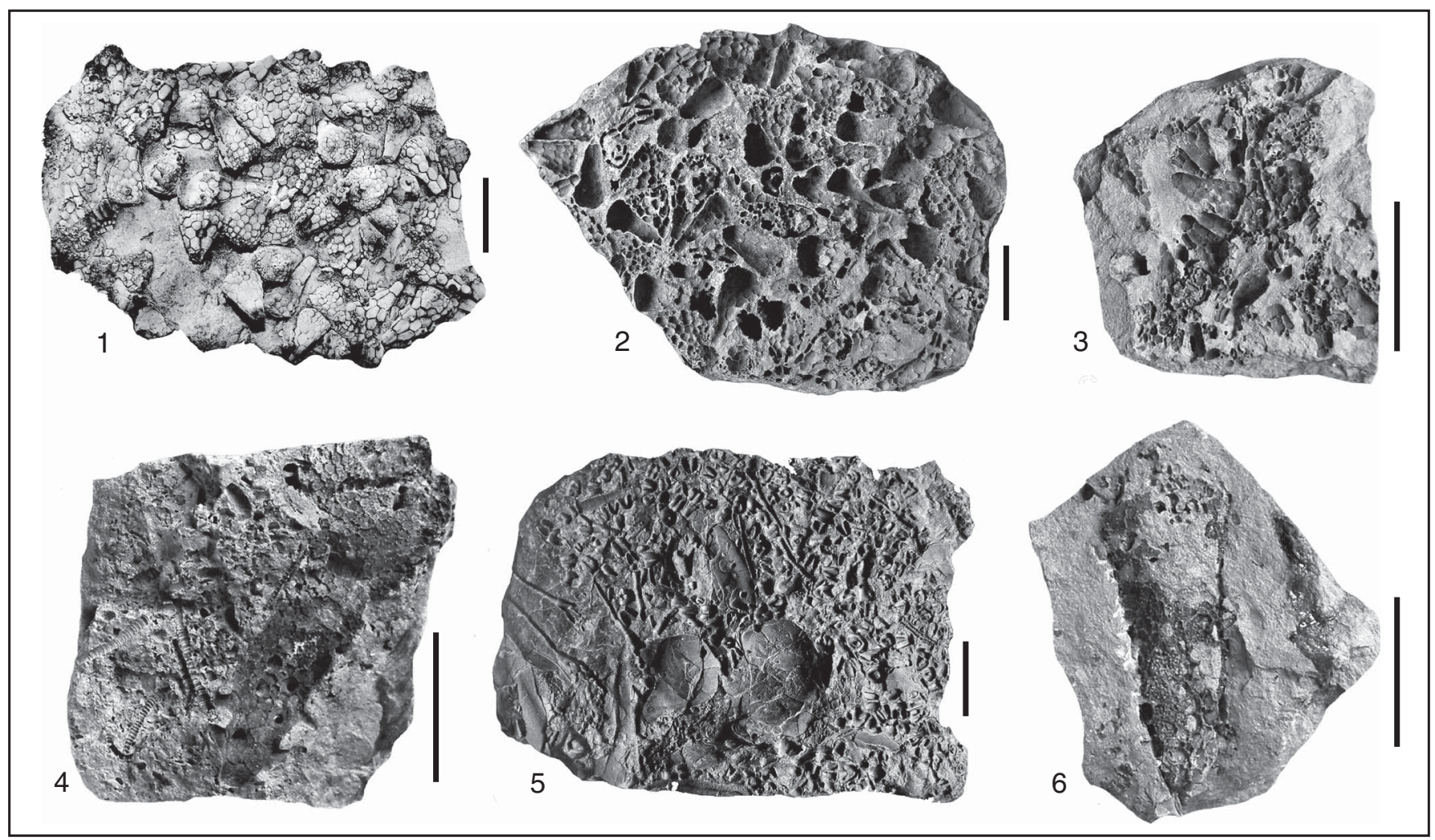

Figure 4. Different types of preservation of Rhopalocystis-dominated assemblages, Lower Ordovician, Zagora area. All photographs show original samples, with the exception of $(\mathbf{1})$ which corresponds to latex cast dusted with ammonium chloride. $(\mathbf{1}, \mathbf{2}, \mathbf{5})$ Type 1 preservation, accumulation of Rhopalocystis spp. within lenses of bioclastic sandstones. (1) $R$. destombesi (ML 20.269.380), accumulation of thecae, locality Z-F25, middle Floian (?B. jacksoni Zone). (2) R. destombesi (UCBL-FSL 711.650), accumulation of thecae, locality Z-F25, middle Floian (?B. jacksoni Zone). (5) Partially disarticulated thecae, portions of stem, and isolated skeletal elements (basal plates) of Rhopalocystis spp. associated with large isolated pieces of trilobites (AA-TISa-OI-10), locality Z-F12c, late Tremadocian (A. murrayi Zone). (3, 4, 6) Type 2 preservation, Rhopalocystis spp. preserved in fine siltstones, locality Z-F1, late Tremadocian (A. murrayi Zone). (3) Complete to slightly disarticulated thecae of Rhopalocystis zagoraensis Chauvel, 1971 (AA-TAM-OI-2). (4) Isolated plates of Rhopalocystis sp. and large theca of Rhopalocystis havliceki Chauvel, 1978 (AA-TAM-OI-21). (6) Large theca of $R$. havliceki (AA-TAM-OI-13). Scale bars $=1 \mathrm{~cm}$.

analyzed data set (Table 1); indeed, most parsimony analysis algorithms (including the one used here) produce consistent results under missing values, which is usually not the case with phenetic approaches. The purpose of this individual-level cladistic analysis was to highlight maximally parsimonious morphological clusters (i.e., clusters obtained under a 'shortest length,' minimum transformation criterion) interpreted here as distinct morphotypes, and thus to emphasize possible species differentiation.

Morphometric analysis.-The thecal geometry of Rhopalocystis is described by six linear dimensions representing lengths and widths of the theca at different levels (Fig. 2.3), measured on the same sample of 58 individuals involved in the cladistic analysis. Missing values in the data set were estimated through multiple imputation using the Amelia II algorithm (Honaker et al., 2011) and following the protocol of Clavel et al. (2014). Raw dimensions were transformed using Mosimann's (1970) log-shape ratio to investigate the geometric shape of the theca independently of interindividual proportional-size differences. With these transformed variables, a principal component analysis (PCA) and a multidimensional analysis of variance (MANOVA) associated to a linear discriminant analysis (LDA) were performed using the PAST software, v. 2.17c (Hammer et al., 2001). The PCA aims to describe the overall interindividual variance structure of the data set, whereas the MANOVA associated with the LDA tests for significance and further describes the between-group morphometric structuring of the clusters highlighted as distinct morphotypes by the cladistic and principal component analyses.

Repositories and institutional abbreviations.-The material examined for this study includes most of the historical samples described in the literature (Ubaghs, 1963; Chauvel, 1971, 1978; Chauvel and Régnault, 1986) and numerous new samples collected in the field since the 2000s in the Zagora area. The historical material includes 49 samples (containing about 250 specimens), most of which are deposited in the collections of the Institut de Géologie de Rennes, France (samples 2082a, b, $1725 h^{\prime}$, M1725a-j, M1725a'-g', M1157a-c, e-g, i-1, o, 1750a,

Figure 3. Synthetic stratigraphic log of the Lower Ordovician succession (modified after Lefebvre et al., 2016b, fig. 2) of the Zagora area (central Anti-Atlas, Morocco) showing the stratigraphic position of the localities $809(=1157=1725), 1750(=1737=1738), 2367$, Z-F1, Z-F12c, and Z-F25 and the distribution of the five species of Rhopalocystis. The sites 2082 and 1773 could not be placed because they are located in a geographically distant area (Agdz). Biostratigraphic data (left columns) are based on graptolite biozones identified by Gutiérrez-Marco and Martin (2016). 
Table 1. Discrete morphological characters and related character states used for the cladistic analysis. The third column refers to specimens illustrated in Figure 5.

\begin{tabular}{|c|c|c|}
\hline Characters & States & Specimens in Figure 5 \\
\hline Thecal size (height) & $\begin{array}{l}\text { Small theca }<4.74 \mathrm{~cm} \\
\text { Large theca } \geq 4.74 \mathrm{~cm}\end{array}$ & $\begin{array}{l}3-13,14,17-20 \\
1,2,16\end{array}$ \\
\hline $\begin{array}{l}\text { Number of circlets } \\
\text { constituting the theca }\end{array}$ & $\begin{array}{l}6 \text { circlets } \\
7 \text { circlets } \\
8 \text { circlets } \\
9 \text { circlets } \\
10 \text { circlets } \\
>10 \text { circlets }\end{array}$ & $\begin{array}{l}8,13 \\
6,7,9,11,14,17,19 \\
5,20 \\
4,10,18 \\
3 \\
1,2,16\end{array}$ \\
\hline Number of radial circlets & $\begin{array}{l}\leq 3 \text { circlets } \\
4 \text { circlets }\end{array}$ & $\begin{array}{l}1,2,3-8,13,18-20 \\
9-12,14,17\end{array}$ \\
\hline $\begin{array}{l}\text { Additional plates between } \\
\text { infralaterals and laterals }\end{array}$ & $\begin{array}{l}\text { Absent } \\
\text { Isolated or incomplete circlet } \\
\text { One complete circlet (with or without } 2 \text { nd incomplete circlet) } \\
\text { Two complete circlets or more }\end{array}$ & $\begin{array}{l}9,13,14,17 \\
6,7,11 \\
5,8,10,12,19,20 \\
3,4,18\end{array}$ \\
\hline $\begin{array}{l}\text { Additional plates between } \\
\text { laterals and radials }\end{array}$ & $\begin{array}{l}\text { Absent } \\
\text { Isolated or incomplete circlet } \\
\text { Complete circlet }\end{array}$ & $\begin{array}{l}6,7,9,11,13,14,17,19,20 \\
3-5,8,12,18\end{array}$ \\
\hline $\begin{array}{l}\text { Rows of additional plates } \\
\text { between laterals }\end{array}$ & $\begin{array}{l}\text { Absent } \\
\text { Present }\end{array}$ & $\begin{array}{l}4,6-9,11,13,17,19,20 \\
3,5,12,18\end{array}$ \\
\hline Radials shape & $\begin{array}{l}\text { Convex } \\
\text { Conical } \\
\text { Globular } \\
\text { Spine-shaped }\end{array}$ & $\begin{array}{l}9-11,14,17 \\
1,3-8,12,18-20\end{array}$ \\
\hline Type of ornamentation & $\begin{array}{l}\text { Absent } \\
\text { Ornamentation folds } \\
\text { (radiating vermiculate ridges) } \\
\text { Nipple-shaped umbo } \\
\text { Granulations } \\
\text { Spine-shaped umbos }\end{array}$ & $\begin{array}{l}17 \\
18-20 \\
14 \\
15 \\
2,16\end{array}$ \\
\hline $\begin{array}{l}\text { Basal plate with vermiculate } \\
\text { ornamentation folds }\end{array}$ & $\begin{array}{l}\text { Absent } \\
\text { Present }\end{array}$ & $\begin{array}{l}-14,17 \\
18-20\end{array}$ \\
\hline
\end{tabular}

1773a, b, 2367a-d, g, h, M2367a-i; Destombes collection). Some other historical samples are registered in the collections of the Muséum d'Histoire naturelle de Nantes, France (samples 2367 SR1-8; Régnault collection) and of the Natural History Museum of Oslo, Norway (samples A 22122, A 29116, A 29120, A29122, A 29124, A 29132, A 29134; Spjeldnaes collection). The new material includes 119 samples (containing about 400 individuals), the bulk of which are deposited in the paleontological collections of the Université Cadi-Ayyad de Marrakech (samples AA.TAM. OI.1-80, AA.TISa.OI.1-27; Lefebvre and RALI collections), Marrakesh, Morocco; some other specimens are registered in the collections of the Musée des Confluences, Lyon, France (samples
ML 20.269.379-382; Reboul collection) and of the Universite Claude Bernard-Lyon 1, Villeurbanne, France (samples UCBLFSL 711.159-711.163, UCBL-FSL 711.650, UCBL-FSL 712.044, 712.045; Reboul collection).

\section{Morphological disparity and species differentiation within the genus Rhopalocystis}

Thecal features.-The unrooted cladogram resulting from the cladistic analysis of 58 Rhophalocystis specimens based on nine discrete morphological characters suggests the distinction of

Figure 5. Illustration of the different states associated with the characters used for the cladistic analysis (see Table 1). (1-13) Drawings realized under a stereomicroscope with a camera lucida; (14-20) photographs of latex casts dusted with ammonium chloride. (1) Rhopalocystis grandis Chauvel, 1971 (holotype 1725a), large-sized theca partially complete, a radius including three globular-shaped radials is visible. (2) R. havliceki (AA-TISa-OI-22j), large-sized well-preserved theca; two radii are visible; the radials are spine-shaped; the infralaterals and some laterals have a spine-shaped umbo more or less elongated. (3) R. zagoraensis (holotype 1725g), elongated theca with three circlets of additional secondary plates between infralaterals and laterals and one incomplete circlet between laterals and radials. (4) R. zagoraensis (AA-TISa-OI-13a), theca with two irregular circlets of additional plates between infralaterals and laterals; the suture between the two visible infralaterals is not vertical, probably as a result of a growth abnormality. (5) R. zagoraensis (2367d1), theca showing one circlet of small secondary plates between infralaterals and laterals; a row of these additional plates is also visible between the laterals. (6) $R$. zagoraensis (AA-TISa-OI-20a), small theca with an incomplete circlet of additional secondary plates between infralaterals and laterals. (7) R. zagoraensis (AA-TISa-OI-21b), small theca with isolated small secondary plates inserted between infralaterals and laterals; the globular shape of the radials is clearly visible. (8) $R$. zagoraensis (AA-TISa-OI-16c), small theca with one complete circlet of additional plates between infralaterals and laterals; the basal is dislocated. (9) $R$. destombesi (ML 20.269.380a); theca constituted of seven well-organized circlets, no additional secondary plate, conical radials. (10) R. destombesi (2367a1), theca showing two additional circlets of secondary plates, one located between infralaterals and laterals, and another one between laterals and infralaterals, conical radials. (11) $R$. destombesi (2367 SR5), theca with one circlet of small secondary plates between infralaterals and laterals. (12) R. zagoraensis (2367c2), aboral part of theca with one complete circlet of additional plates between infralaterals and laterals, and a row of additional plates inserted between laterals; three radii can be observed, each composed of one column of four globular-shaped radials. (13) Rhopalocystis fraga Chauvel, 1971 (1725g'1), theca composed of six circlets of plates including three circlets of convex radials. (14) $R$. destombesi (1157e1, right side, and $1157 \mathrm{e} 2$, left side), specimens having nipple-shaped umbos centered in the middle of most of their thecal plates. (15) $R$. grandis (AA-TISa-OI-5), fragment of theca constituted of irregular plates covered with small granulations. (16) $R$. havliceki (AA-TAM-OI-9), large-sized theca; the aboral extremity is missing; numerous laterals exhibit a spine-shaped relatively elongated umbo. (17) R. destombesi (2367b1), unornamented specimen with smooth thecal plates. (18-20) $R$. zagoraensis, thecae showing more or less continuous ornamentation folds, basals with vermiculated folds. (18) UCBL-FSL 712.044a. (19) AA-TISa-OI-16a. (20) AA-TISa-OI-17e. (1, 3, 13, 14) Locality 809 (=1157 = 1725), late Tremadocian (A. murrayi Zone); (2, 4, 6-8, 15, 18-20) locality Z-F12c, late Tremadocian (A. murrayi Zone); (9) locality Z-F25, middle Floian (?B. jacksoni Zone); (5, 10-12, 17) locality 2367, late Tremadocian (H. copiosus Zone); (16) locality Z-F1, late Tremadocian (A. murrayi Zone). Scale bars $=1 \mathrm{~cm}$. 


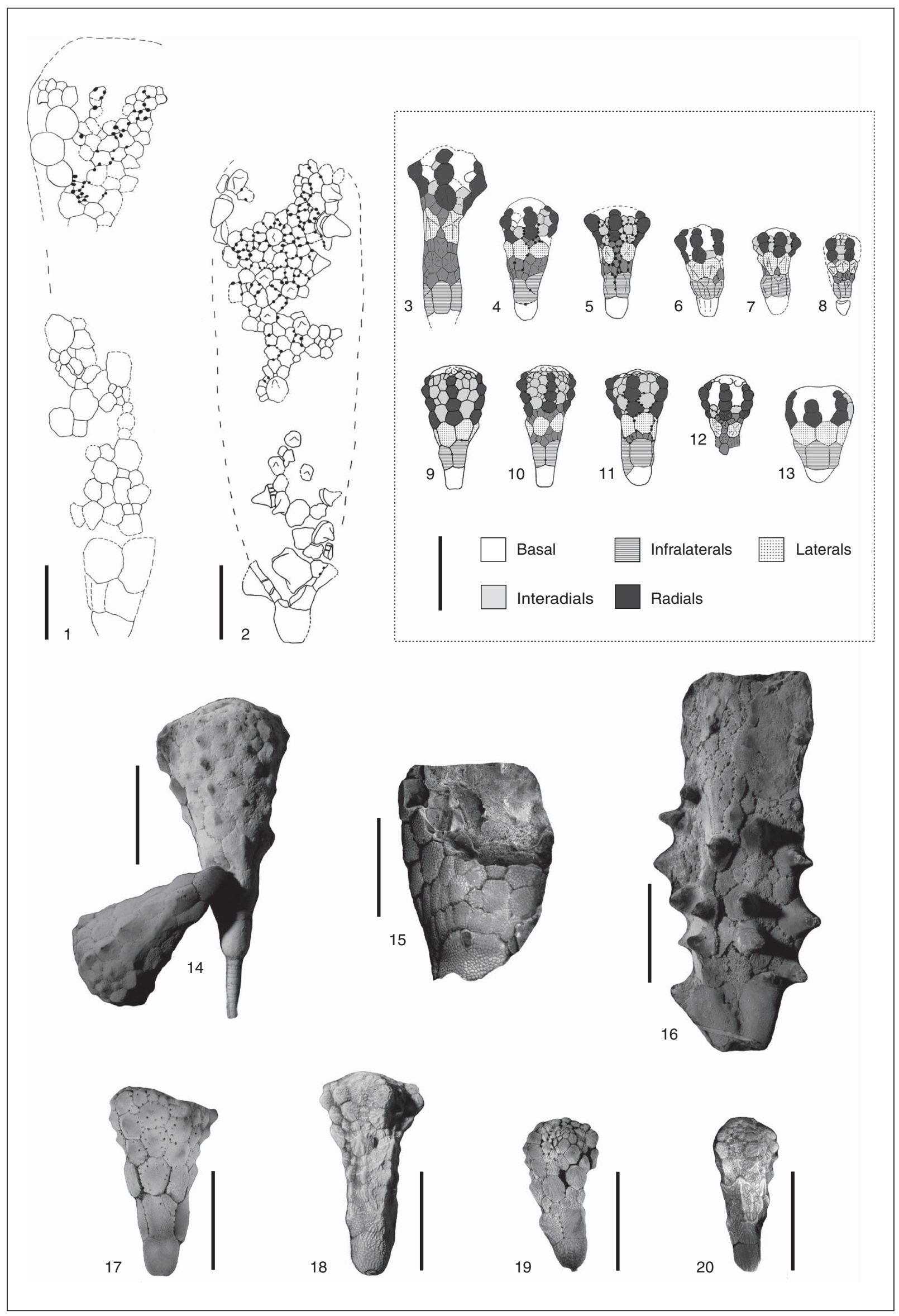



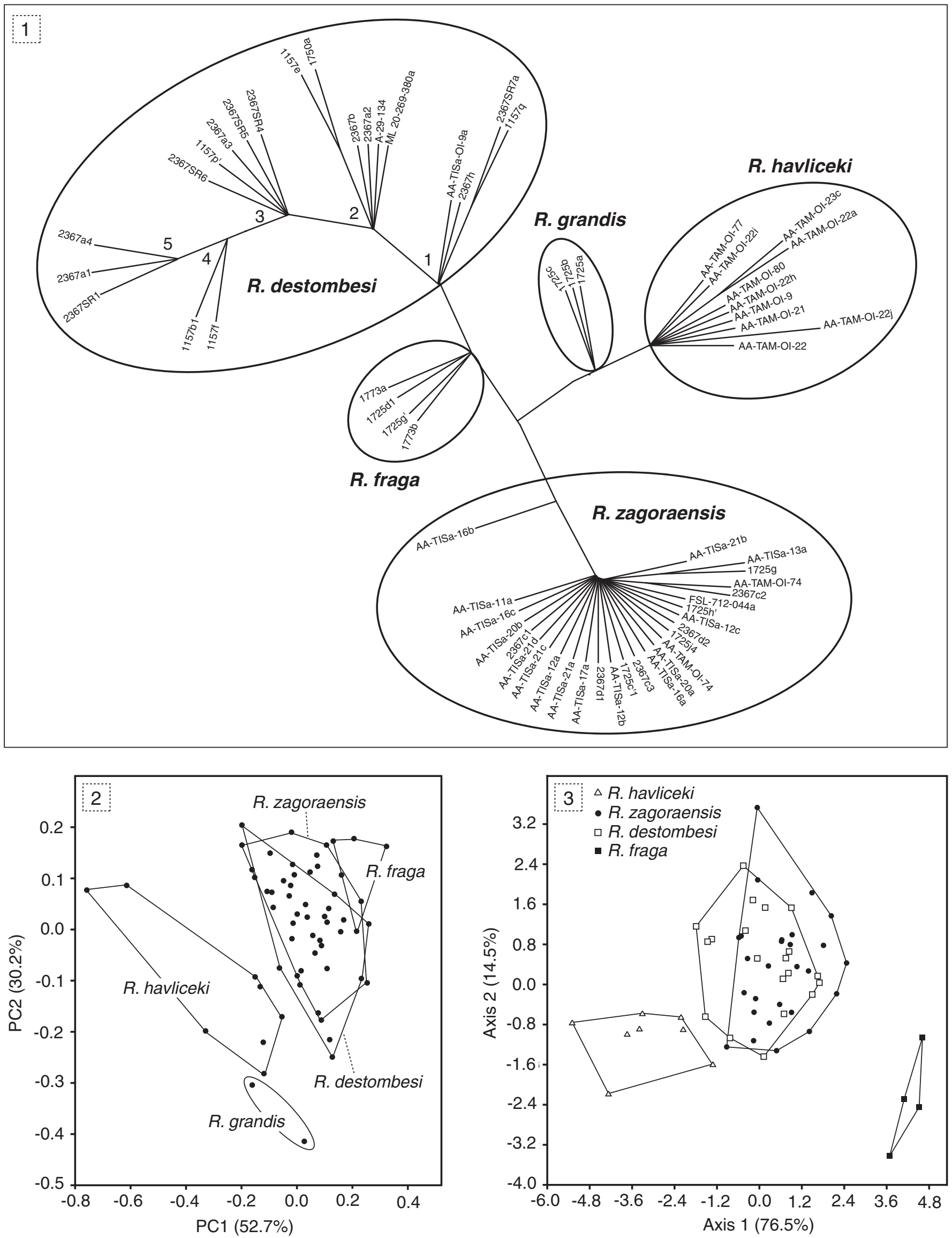
five morphological groups (Fig. 6.1). The main characters allowing the discrimination of these groups correspond to the thecal size (thecal length; character positively correlated to the number of circlets constituting the theca), the shape of the radials, and the type of ornamentation. Two main clusters of taxa can be separated according to their thecal size: small-sized morphotypes $(R$. destombesi, $R$. fraga, $R$. zagoraensis $)$ and large-sized morphotypes ( $R$. grandis, $R$. havliceki). The shape of the radials and the type of ornamentation both allow the discrimination of five groups: $R$. fraga (convex radials and usually unornamented, smooth plates), $R$. havliceki (spine-shaped radials and ornamentation corresponding to spine-shaped protuberances), $R$. grandis (globular-shaped radials and plates covered with granulations), $R$. destombesi (conical radials and usually no ornamentation), and $R$. zagoraensis (globular-shaped radials and ornamentation folds). The number of radial circlets allows differentiation of $R$. destombesi (with four radial circlets) from the four other morphotypes (with three radial circlets). The presence of additional secondary plates (Table 1; Fig. 5) corresponds to a specific feature that has been only considered to discriminate the small-sized morphotypes ( $R$. fraga, $R$. destombesi, $R$. zagoraensis). Thus, the thecal plating of $R$. fraga (with no secondary plates) appears clearly distinct from those of $R$. destombesi and $R$. zagoraensis (which can both have secondary plates).

Three clusters correspond to the morphotypes $R$. fraga, $R$. grandis, and $R$. havliceki. The $R$. fraga cluster is characterized by a small theca $(<4.74 \mathrm{~cm})$ composed of six well-defined plate circlets, including three radial circlets with slightly convex plates. The $R$. grandis cluster is distinguished by a large theca $(>4.74 \mathrm{~cm})$ consisting of more than 10 plate circlets. The radial plates (three circlets) are globular in shape. Except the radials, all thecal plates are covered with small punctiform granulations. The $R$. havliceki cluster is defined by a large theca $(>4.74 \mathrm{~cm})$ composed of more than 10 plate circlets and a specific ornamentation formed by spine-shaped protuberances.

The two other clusters correspond to the specimens respectively identified as $R$. destombesi and $R$. zagoraensis. Despite their apparent similarities (small size, possible presence of additional secondary plates), they show clearly distinct morphological characteristics. The $R$. destombesi cluster is characterized by a theca composed of seven primary plate circlets (including four radial circlets). The radial plates are conical (with a blunt summit). The thecal plates are usually smooth (without ornamentation). The $R$. zagoraensis cluster possesses a theca composed of six primary plate circlets (including three radial circlets). The radial plates are globular in shape. The thecal plates are covered with a typical ornamentation (folds). The basal plate can be split into two distinct elements.

Concerning $R$. destombesi, the cladistic analysis also suggests the presence of five subgroups. These subgroups illustrate a morphological variability (polymorphism) consistent with the taxonomic descriptions of $R$. destombesi (see Ubaghs, 1963; Chauvel and Régnault, 1986). The radial plates of some specimens do not show the typical conical morphology, but are simply convex (subgroup 1, Fig. 6.1); some of these individuals exhibit a large theca ( $>4.74 \mathrm{~cm}$, specimens $2367-S R 7 \mathrm{a}, 1157 \mathrm{q})$. The morphology of several specimens fits exactly the original description of Ubaghs (1963), with a theca composed of seven well-defined circlets of plates, with three circlets of conical radial plates (subgroup 2, Fig. 6.1). Among this subgroup, some specimens exhibit a particular ornamentation, consisting of a nipple-shaped central umbo (specimens 1157e, 1750a). Individuals belonging to the three other subgroups also show conical radials. However, they possess complex thecal plating with secondary plates intercalated within the seven primary circlets. Some specimens only have few additional plates located between infralaterals and laterals, and either consisting of isolated plates or forming an incomplete circlet (subgroups 3, 4, Fig. 6.1). The specimens belonging to subgroup 4 specifically possess only three circlets of radials, while those belonging to subgroup 3 have four circlets of radials (as all individuals belonging to the other subgroups). Finally, the fifth subgroup is defined by the presence of a complete additional circlet of secondary plates inserted between infralaterals and laterals (subgroup 5, Fig. 6.1).

Contrary to the situation in $R$. destombesi, the result of the cladistic analysis did not illustrate the polymorphism previously suggested in the descriptions of $R$. zagoraensis (e.g., Chauvel, 1978; Chauvel and Régnault, 1986). The intraspecific morphological variability of $R$. zagoraensis largely results from variations in ornamentation intensity. In individuals assigned to $R$. zagoraensis, the ornamentation varies from weak (sometimes reduced to ridges on the basal) to extremely strong (all thecal plates covered with continuous ridges converging toward the center of larger skeletal elements). The coding of the ornamentation in the cladistic analysis was based on large categories leading to the same coding for weakly to strongly ornamented specimens. Thus, the cladistic analysis does not reflect the important polymorphism, mainly expressed as variations in the ornamentation, which characterizes the species $R$. zagoraensis.

Thecal geometry.-The variability in thecal geometry within the genus Rhopalocystis was first investigated using a principal component analysis based on six log-shape ratio transformed linear dimensions (Fig. 2.3). The resulting morphospace (82.9\% of the overall interindividual variance described by the two first principal components; Fig. 6.2) shows relatively homogeneous thecal geometries among the genus Rhopalocystis, except for three outliers (TAM-OI-21, TAM-OI-22, 1725a). The first principal component, accounting for $52.7 \%$ of the total variance, separates the length of the different regions of the theca (adoral thecal length anticorrelated with aboral thecal length) and the maximum radial width. Minor separation occurs along the

Figure 6. (1) Unrooted most parsimonious tree (based on Wagner parsimony) separating the five morphotypes identified within the genus Rhopalocystis: $R$. destombesi, $R$. fraga, $R$. zagoraensis, $R$. havliceki, and $R$. grandis. Length $=41$; consistency index $=0.536$; retention index $=0.906$; rescaled consistency index $=0.486$. (2) Multivariate interindividual variability in the thecal geometry of Rhopalocystis. First principal plane (showing $82.9 \%$ of the total interindividual variance) of the morphospace resulting from the principal component analysis. (3) Multivariate interspecies variability in the thecal geometry of Rhopalocystis. First discriminant plane (showing $91.0 \%$ of the total among-group variance) of the morphospace resulting from the linear discriminant analysis. 
second principal component (30.2\% of the total variance), focusing on the maximum width of the laterals negatively correlated with the maximum width of both basal and infralaterals.

The thecal geometry of Rhopalocystis varies continuously from a conical shape associated with a tenuous or large aboral region (lower left and lower right quadrants, respectively) to an inflated claviform geometry associated with a narrow basis and an elongate aboral region (upper left quadrant) via a moderate obconical morphology associated with a long adoral region (upper right quadrant). The cladistically defined morphotypes $R$. fraga, $R$. grandis, and $R$. havliceki are located in the periphery of the scatter plot (Fig. 6.2). The morphotype $R$. fraga is distinguished by a conical theca with both basal and infralaterals as wide as the laterals, and a narrow and elongate adoral region. The large morphological variability shown by the two other morphotypes ( $R$. grandis, $R$. havliceki) is more difficult to interpret because of the reduced number of individuals. The last two morphotypes, $R$. destombesi and $R$. zagoraensis, are largely overlapping in the center of the PCA plot, thus suggesting a similar but variable thecal geometry (Fig. 6.2).

A MANOVA associated to a linear discriminant analysis (LDA) was performed to test the validity of the morphotypes identified by the cladistic analysis and further recognized pro parte by the PCA. The species $R$. grandis could not be included in these analyses because measurements could be made only on two complete specimens (1725a, b; the third available specimen of $R$. grandis, $1725 \mathrm{c}$, corresponds to a fragment of the aboral part of a theca; see Systematic Paleontology). The MANOVA evidences a highly significant multivariate difference between the four remaining species: Wilk's $\lambda=0.087$, d.f. $=24,179.1$, Rao's $F=7.56, p=5.4 \times 10^{-17}$. The post hoc contrast analysis (pairwise comparisons, using Hotelling's $\mathrm{T}^{2}$ tests coupled with a sequential Bonferroni's correction for multiple testing) shows highly significant differences for four of the six species couples, a marginally to nonsignificant difference between $R$. fraga and $R$. havliceki, and a nonsignificant difference between $R$. destombesi and $R$. zagoraensis, indicating that these two species cannot be distinguished geometrically on the basis of these six linear descriptors (Table 2). The LDA correctly assigns $75 \%$ of the specimens to their predefined morphotypes, with all misclassifications occurring between $R$. destombesi and $R$. zagoraensis, as expected from the contrast analysis (Fig. 6.3).

Discussion.-The cladistic and morphometric analyses together indicate that the genus Rhopalocystis may be constituted of five distinct morphological species. Both analyses show that the three morphological species $R$. fraga, $R$. grandis, and $R$. havliceki can be readily distinguished on their dimensional geometry and on the organization and ornamentation of

Table 2. Results of the contrast analysis (pairwise comparisons, using Hotelling's $\mathrm{T}^{2}$ tests coupled with a sequential Bonferroni's correction for multiple testing) associated with the MANOVA.

\begin{tabular}{llll}
\hline & $R$. fraga & R. destombesi & $R$. zagoraensis \\
\hline$R$. destombesi & 0.00055292 & & \\
$R$. zagoraensis & 0.00013658 & 0.30292 & \\
R. havliceki & 0.066057 & 0.00013673 & $1.75 \mathrm{E}-06$ \\
\hline
\end{tabular}

the theca. $R$. fraga has a small, strawberry-shaped theca, composed of five circlets of plates and a wider than high basal plate. $R$. grandis is a large-sized species. Its radial plates are almost hemispherical, and most of its thecal plates are ornamented with small punctiform granulations. $R$. havliceki also has a largesized theca; its radials and some of its laterals are spine-shaped, and its infralaterals are ornamented with one to three elongated protuberances.

The morphometric analysis shows that the two morphological species $R$. destombesi and $R$. zagoraensis share comparable thecal geometries, mostly based on similar thecal length-width proportions. However, the specimens belonging to $R$. destombesi could reach a greater size: the theca of the longest specimen measures $50 \mathrm{~mm}$, while the longest specimen observed for $R$. zagoraensis reaches only $21 \mathrm{~mm}$. Moreover, the cladistic analysis illustrates that these two species can be easily distinguished by the organization of the theca, its ornamentation, the number of radial circlets, and the shape of radial plates. In $R$. zagoraensis, the theca is usually composed of six primary plate circlets (including three radials circlets) instead of seven primary plate circlets (comprising four radial circlets) in $R$. destombesi. In $R$. zagoraensis, radials are globular (almost hemispheric, while they can also be convex), but they are more frequently conical with a blunt summit in $R$. destombesi. The thecal plates of $R$. destombesi are usually smooth, whereas those of $R$. zagoraensis are covered with vermiculated radiating ridges. Moreover, the examined specimens of $R$. destombesi never showed more than one circlet of secondary plates between the infralaterals and the laterals. By contrast, the theca of $R$. zagoraensis exhibits a high number of additional secondary plates, with up to three intercalary circlets between infralaterals and laterals. Finally, the basal plate in $R$. zagoraensis can be split to two elements.

$R$. destombesi, $R$. zagoraensis, and R. havliceki show a relatively large polymorphism. The variability of $R$. destombesi mainly results from the complexity of the thecal plating, ranging from none to two additional complete intercalary circlets (one between infralaterals and laterals, and another between laterals and radials). The thecal plates are usually smooth, but they sometimes show a nipple-shaped central umbo. In $R$. zagoraensis, the polymorphism is more pronounced. The thecal plating varies strongly because of the varying size and number of secondary plates, either isolated or organized in complete circlets: one to three circlets intercalated between infralaterals and laterals and another complete one between laterals and radials. Moreover, the particular ornamentation of $R$. zagoraensis varies strongly: it can range from being restricted to small vermicular ridges on the basal plate to very extensive and consisting of continuous and elongated folds all over the theca.

The morphological variability in $R$. havliceki concerns the ornamentation. Its infralaterals and laterals bear one, two, or three rounded to spine-shaped umbos. Some differences in the ornamentation can be observed between the populations coming from the localities Z-F1 and Z-F12c. The Z-F1 specimens exhibit only one spine-shaped protuberance, whereas those from Z-F12c show one, two, or three rounded protuberances on their laterals. This variation might reflect either environmental differences between their habitats or evolutionary adaptations. 


\section{Systematic paleontology}

\author{
Class Eocrinoidea Jaekel, 1918 \\ Order Ascocystitida Frest, 2005 \\ Family Rhopalocystidae Frest, 2005 \\ Genus Rhopalocystis Ubaghs, 1963
}

Type species.—Rhopalocystis destombesi Ubaghs, 1963 from the Destombes locality $809(=1157=1725)$, Zagora area, central Anti-Atlas (Morocco), by original designation.

Other species.- $R$. fraga Chauvel (1971), R. grandis Chauvel (1971), R. zagoraensis Chauvel (1971), and R. havliceki Chauvel (1978).

Diagnosis.-Claviform theca composed of thick plates bearing circular to elliptical epispires on their margins, pentameral symmetry expressed by the plating of radial circlets, unique and thick basal cup-shaped plate, four pentagonal to hexagonal infralaterals, at least six laterals, five short embedded ambulacra with four to eight plates each bearing long biserial brachioles swollen at their base; lateral periproct on the adoral CD interray, long slowly tapering holomeric stem.

Occurrence.-Middle Tremadocian (A. victoriae Zone) to middle Floian (?B. jacksoni Zone), Fezouata Shale, AgdzZagora area, central Anti-Atlas, Morocco.

Remarks.-The original diagnosis of the genus Rhopalocystis (Ubaghs, 1963), was successively modified by Ubaghs (1968) and Sprinkle (1973). It is further emended here to clarify the main characteristics defining the singular morphology of this genus. Fairly good pentameral symmetry is indicated by five perradial areas (each composed of one column of radial plates) and five interradial areas (composed of more numerous plates generally less organized).

Several small specimens of eocrinoids (thecal length 5-8 mm) coming from locality 2367 were described by Chauvel and Régnault (1986, text-fig. 4). They were interpreted as putative juvenile individuals of either Rhopalocystis or Balantiocystis (Chauvel and Régnault, 1986) or, alternatively, assigned to a new, yet undescribed, genus of small, nail-shaped eocrinoids, possibly related to Ascocystites cuneiformis Chauvel, 1941 (Lefebvre et al., 2016b). Their thecae are composed of four well-organized circlets of plates (one very small basal, four infralaterals, six laterals, and five radials; no interradial plates). The oral surface contains the peristome surrounded by five simple brachioliferous areas (Chauvel and Régnault, 1986). The new material did not yield this type of small specimens, but one of those figured by Chauvel and Régnault (1986, text-fig. 4) was reexamined in this study (specimen M.2367dE). A long and slender stem is preserved articulated to the theca; it is made up of small cylindrical columnals of different lengths. Numerous well-preserved specimens of Rhopalocystis were collected in the level yielding the small individuals (locality 2367), but no specimens of Balantiocystis were observed. These small specimens could therefore correspond to juvenile individuals of Rhopalocystis sp.
Rhopalocystis destombesi Ubaghs, 1963

Figures 2, 4.1, 4.2, 5.9-5.11, 5.14, 5.17, 7, 8

1963 Rhopalocystis destombesi Ubaghs, p. 27, pl. 1-3, textfigs. 1-9.

1968 Rhopalocystis destombesi; Ubaghs, S481, text-figs. 292, 293, 298, 310.

1971 Rhopalocystis destombesi; Chauvel, p. 46, pl. 2, fig. 4.

1973 Rhopalocystis destombesi; Sprinkle, p. 110.

1986 Rhopalocystis destombesi; Chauvel and Régnault, p. 865 , pl. 1 , figs. $1-4$, text-fig. $3 \mathrm{~A}-\mathrm{E}$.

1986 Rhopalocystis dehirensis; Chauvel and Régnault, p. 865, pl. 1, figs. 5-8, text-fig. 3F-H.

2007 Rhopalocystis destombesi; Guensburg and Sprinkle, p. 283, text-fig. 3B.

2013 Rhopalocystis destombesi; Kammer et al., p. 4, text-fig. 2A, B, D, E.

2013 Rhopalocystis destombesi; Lefebvre et al., p. 182, textfig. 14.8b.

2015 Rhopalocystis destombesi; Allaire et al., p. 24, text-fig. 2B-D, F.

2016 Rhopalocystis destombesi; Guensburg et al., p. 263, textfig. 8A.

2016b Rhopalocystis destombesi; Lefebvre et al., p. 13, text-fig. 8D.

Holotype.-Samples A29134 and A29120 (part and counterpart) from the Fezouata Shale, Zagora area (locality 809; Fig. 1), Anti-Atlas, Morocco (Ubaghs, 1963, p. 27, pl. 2, figs. 2, 3, pl. 3, fig. 1 , text-fig. 1).

Diagnosis.-Rhopalocystis with a theca composed of seven primary circlets of plates, one basal circlet (a single plate), one infralateral circlet (four plates), one lateral circlet (six plates), four radial circlets consisting of five perradial areas (each composed of one column of four radial plates), and five interradial areas composed of plates arranged in four to five successive rows. Infralateral and lateral circlets joined or separated by additional secondary plates (isolated or forming one circlet); some additional secondary plates can be also present between the lateral and the first radial circlet. Radial plates conical-shaped, with a blunt summit. Thecal plates without ornamentation (smooth surface) or exhibiting a central, nipple-shaped umbo.

Occurrence.-Middle Tremadocian (A. victoriae Zone) to middle Floian (?B. jacksoni Zone), Fezouata Shale, Agdz-Zagora area, localities $809(=1157=1725), 1737(=1738=1750), 2367$, Z-F12c, and Z-F25 (Fig. 3), central Anti-Atlas (Morocco).

Description.-The theca of $R$. destombesi consists of seven primary circlets of well-organized and sutured plates with three aboral circlets of plates (a single basal, four infralaterals, six laterals) surmounted by 10 columns of plates: five meridian areas (consisting of radials and supraradials) and five interradial areas (formed of a higher number of elements; one of these areas contains the periproct). The oral surface, the morphology of the ambulacra and the peristome, the respiratory structures, the brachioles, and the stem were described with great accuracy by Ubaghs (1963, p. 26-37). This well-organized and regular thecal morphology is clearly visible in most specimens 

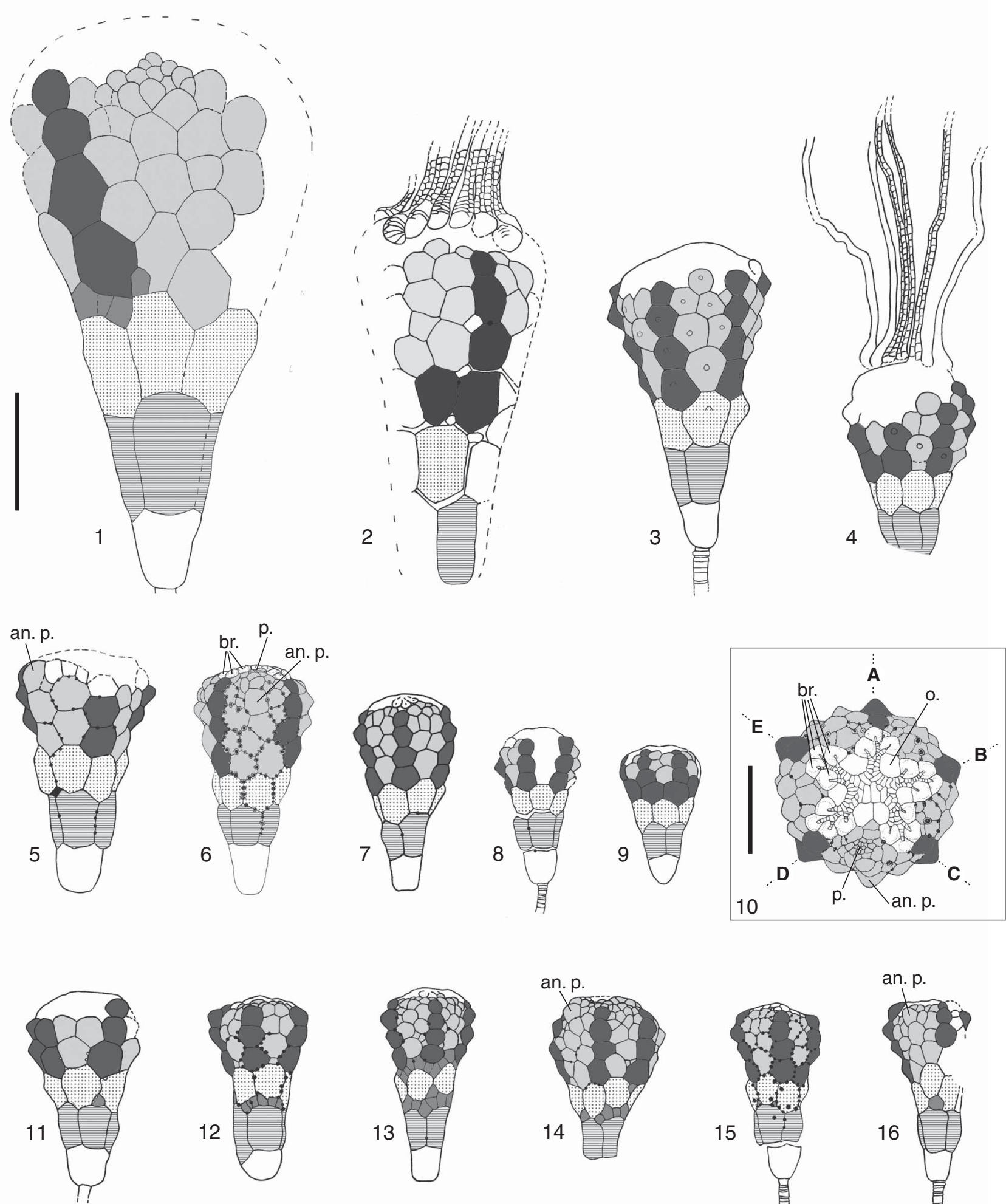
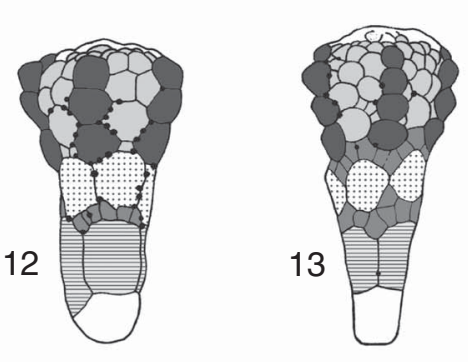

an. p.

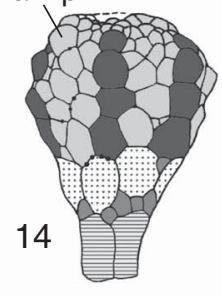

$\begin{array}{ll}\text { Infralaterals } & \text { Laterals } \\ \text { Interadials } & \square \text { Radials }\end{array}$ an. p.

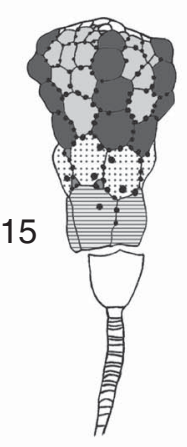

16

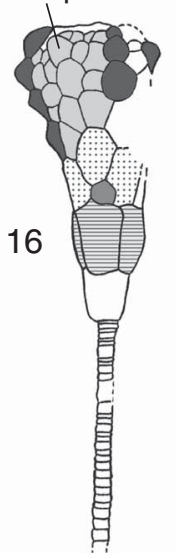


(e.g., Figs. 2, 5.9, 5.14, 5.17, 7.2-7.9, 8.1, 8.2, 8.7, 8.9, 8.10). However, some individuals have one or more additional secondary plates. These additional elements can consist of isolated plates, localized between infralaterals and laterals and/or between the laterals and the first radial circlet (e.g., Figs. 7.11, 7.15, 7.16, 8.6). In some other specimens, these additional plates can form a circlet (complete or incomplete) between infralaterals and laterals (Figs. 5.11, 7.12, $7.14,8.3,8.5$ ). Some specimens have two circlets of intercalary plates: one between infralaterals and laterals and one between the laterals and the first radial circlet (e.g., Figs. 5.10, 7.13, 8.4).

The thecal length of the studied specimens varies from 12 to $50 \mathrm{~mm}$. Some individuals are particularly large (e.g., Figs. 7.1-7.3, 8.7, 8.8, 8.10); however, most observed specimens have a thecal length between 15 and $20 \mathrm{~mm}$.

Generally, radial plates have a relatively conical shape with a blunt summit, usually more accentuated for the third radial plate (e.g., Figs. 2, 5.9-5.11, 7.3, 7.5-7.8, 7.10-7.16, 8.1-8.6, $8.9,8.10)$. The radial plates relief can be more or less pronounced; in some specimens, the radials are simply convex (e.g., Figs. 7.1, 7.2, 7.9, 8.7, 8.8). In most specimens, the external surface of thecal plates is entirely smooth. However, in a few individuals, almost all thecal plates show a central, nippleshaped umbo (e.g., Figs. 5.14, 7.3, 7.4, 8.9, 8.10; already observed by Chauvel, 1971, pl. 2, fig. 4).

The stem of $R$. destombesi is composed of cylindrical columnals becoming thinner distally (see Ubaghs, 1963, textfig. 1). The proximal part of the stem is composed of an alternation of very short and longer columnals (e.g., Figs. 2.4, 2.5, 7.15, 7.16, 8.6, 8.10); this difference disappears progressively distally, as the diameter of the stem decreases. The newly collected material did not yield any specimen showing the distal extremity of the stem. The proximal part is often preserved in connection with the theca, but the distal part of the stem is always missing. Only a few isolated distal fragments could be observed. As mentioned by Ubaghs (1963), the best-preserved stems of $R$. destombesi (Fig. 2.4) do not show any evidence of the attachment structure at their distal tip.

The brachioles are rarely preserved (Figs. 2.4, 7.2, 7.4, 8.8, 8.9). As indicated by Ubaghs (1963), they are biserial and swollen in their proximal part. Particularly well-preserved and long brachioles can be observed in specimen 1750a (Figs. 7.4, 8.9; not figured by Ubaghs): although their distal tip is missing, they were certainly twice as long as the theca.

The morphology of the oral surface - the ambulacra, the peristomial area, the periproct (posterior interradial area), and the respiratory structures (epispires) — was perfectly described by Ubaghs (1963) and is not further elaborated here (see Ubaghs, 1963, text-figs. 1-8).

Materials.-Seven latex casts of original samples described by Ubaghs (1963): the holotype A 29120 and A 29134 (part and counterpart), A 22122, A 29116, A29122, A 29124, A 29132, A (locality $809=1157=1725$; Fig. 1), and 1750a, b (locality $1737=1738=1750$; Fig. 1). Several latex casts realized of original specimens of Chauvel $(1971,1978)$ and Chauvel and Régnault (1986): 1157a, b1, c, e-g, i-l, o, p, p', q, and M1725a' (locality $809=1157=1725$; Fig. 1); and 2367a1-a4, b1, e, f (f1, f2), g-i (locality 2367; Fig. 1). Original samples from locality 2367 (Fig. 1): 2367a, b, f, h, i and 2367 SR1, 4-7. One sample from locality Z-F12c (Fig. 1): AA-TISa-OI-9. Eleven samples with numerous external molds of thecae coming from Z-F25 (Fig. 1): ML 20.269.379-382, and UCBL-FSL 711.159163, UCBL-FSL 711.650.

Remarks.-Numerous specimens possess supplementary plates (secondary plates, isolated or forming complete circlets) in addition to the seven primary circlets described by Ubaghs (1963). The presence of these additional secondary elements is not a simple by-product of allometric growth: many specimens having a small size possess additional plates (up to two circlets; e.g., Figs. 7.13, 8.4), while other specimens having a larger size have no additional plates, or only isolated ones (e.g., Fig. 7.17.3). For these large individuals, the primary circlets of plates are joined and comprise elements whose size is proportionally large, illustrating a holoperipheric growth mode. This suggests that the theca of $R$. destombesi could grow in two ways: a simple holoperipheric growth of the plates forming the seven primary circlets of the theca and by inserting new plates (additional secondary plates) between some of these main circlets.

Consequently, the diagnosis of $R$. destombesi (unchanged since Ubaghs, 1963) was emended to underscore the main characteristics of the species and to consider its morphological variability partly caused by the potential presence of additional secondary plates.

Chauvel and Régnault (1986, text-fig. 3A-E) identified some specimens of $R$. destombesi showing additional secondary plates inserted between laterals and infralaterals, and between laterals and radials (as isolated plates or forming incomplete circlets). Only one of them could be examined (1157b1, Fig. 7.11). It shows a small secondary plate between the infralaterals and laterals, and its morphology fits well with the species $R$. destombesi. The other specimens $1157 \mathrm{~m}$, $\mathrm{n}$, and o/1 figured by Chauvel and Régnault (1986, text-fig. 3A, C-E) could not be reexamined, but according to the description and drawings of the authors, the morphological features of these individuals seem to support their assignment to $R$. destombesi.

Ubaghs (1963, text-fig. 9) described a specimen of $R$. destombesi that he considered as abnormal due to the presence of additional plates intercalated between infralaterals and laterals, and between the laterals and the first radial circlet. Chauvel and Régnault (1986, text-fig. 3G) identified this

\footnotetext{
Figure 7. Rhopalocystis destombesi, drawings realized under a stereomicroscope with a camera lucida. (1) $1157 \mathrm{q} 1 ;$ (2) $2367 \mathrm{~h} ;(\mathbf{3}) 1157 \mathrm{e} 1 ;(\mathbf{4}) 1750 \mathrm{a} 1 ;(\mathbf{5})$ 2367b1; (6) holotype (A29134 and A29120, part and counterpart), drawing modified from Ubaghs (1963, text-fig. 2.2); (7) ML 20.269.380a; (8) 2367f1; (9) AATISa-OI-9a; (10) oral surface of the theca showing the conical radials, the five ambulacra, the brachioliferous plates, the peristomial area, and the anal region containing the periproct, (holotype A29134 and A29120, part and counterpart), drawing modified from Ubaghs (1963, text-fig. 2.3); (11) 1157b1; (12) 2367 SR5; (13) 2367a1; (14) 2367 SR1; (15) 2367 SR6; (16) 2367a3. (1, 11-16) Specimens showing seven primary circlets of plates and additional secondary plates, as isolated plates or forming one complete or incomplete circlet, which can be inserted between infralaterals and laterals, and between laterals and radials; (2-9) specimens possessing only the seven primary circlets of plates that characterize the species, without additional secondary plates. $(\mathbf{1 , 3 , 6 , 1 0 , 1 1 ) ~ L o c a l i t y ~} 809$ $(=1157=1725)$, late Tremadocian $($ A. murrayi Zone) $;(\mathbf{2}, \mathbf{5}, \mathbf{8}, \mathbf{1 2}-\mathbf{1 6})$ locality 2367 , late Tremadocian $($ H. copiosus Zone); (4) locality $1750(=1737=1738)$, late Tremadocian (A. murrayi Zone); (7) locality Z-F25, middle Floian (?B. jacksoni Zone); (9) locality Z-F12c, late Tremadocian (A. murrayi Zone). $\mathrm{p} .=$ periproct; an. $\mathrm{p} .=$ anal protuberance; br. $=$ brachioliferous plates; $\mathrm{o} .=$ oral plates. $(\mathbf{1 - 9 ,}, 11-16)$ Scale bar $=1 \mathrm{~cm} ;(\mathbf{1 0}) \mathrm{scale}$ bar $=5 \mathrm{~mm}$.
} 


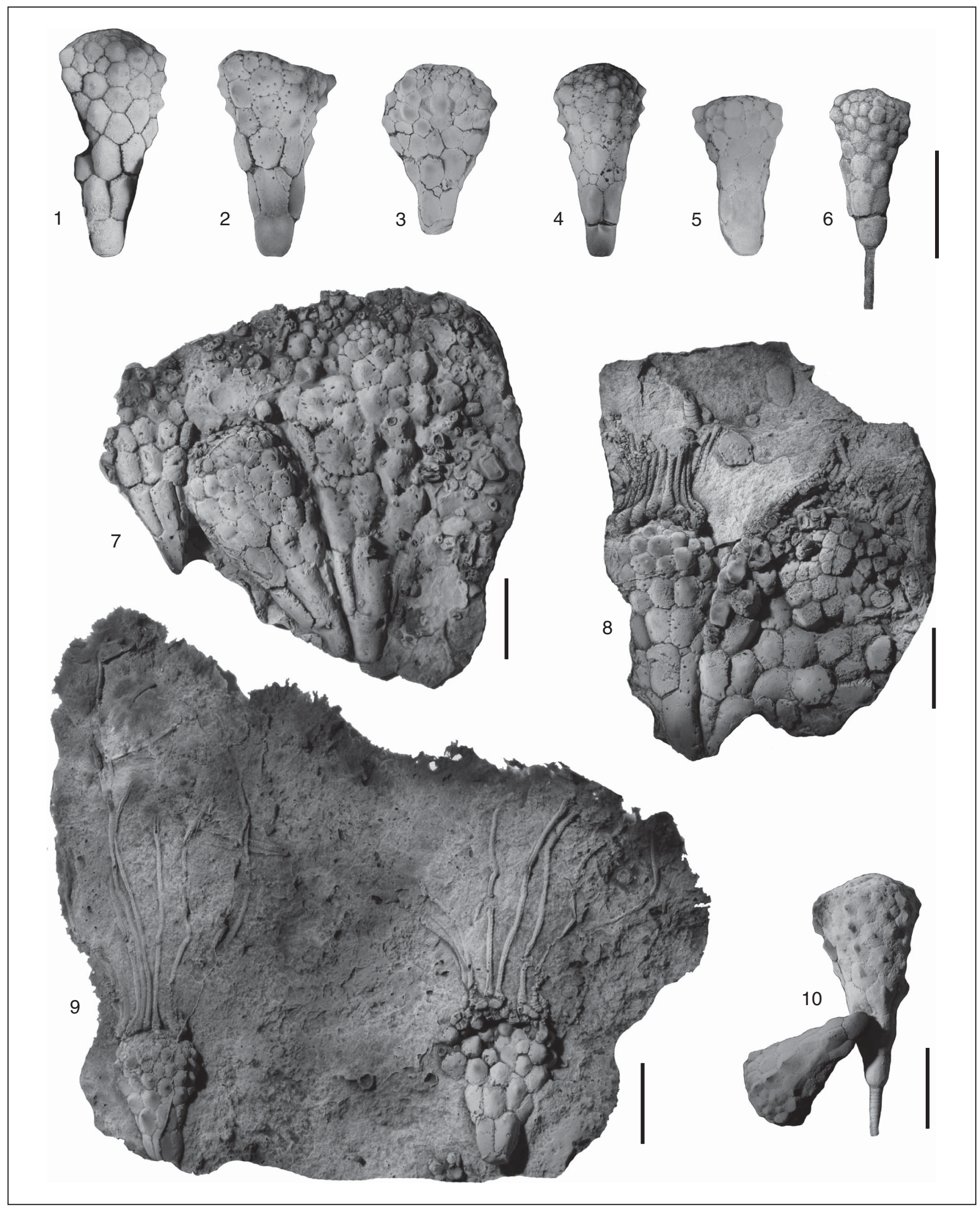


specimen as $R$. dehirensis. They erected this new species to group all individuals corresponding to the description of $R$. destombesi but having one complete circlet of plates between infralaterals and laterals. Numerous intermediate states can be observed, ranging from one isolated additional plate to a complete circlet. This points toward the existence of one single species $(R$. destombesi) showing relatively important morphological variations. Therefore, the morphology of Ubaghs' 'abnormal' individual now appears to be entirely consistent with the intraspecific variability observed for $R$. destombesi. This identification is supported by the presence of four circlets of conical radial plates and by the absence of ornamentation on the thecal plates (smooth plates).

Two other specimens (2367a 1 and $1157 \mathrm{~h})$ were identified as $R$. dehirensis by Chauvel and Régnault (1986, text-fig. 3F, H). The specimen 2367a1 (Figs. 7.13, 8.4) was reexamined. It possesses two circlets of additional secondary plates (one between infralaterals and laterals and one between laterals and radials) and exhibits all morphological characteristics of the species $R$. destombesi (six primary circlets of plate, with four circlets of conical radials, no ornamentation). The specimen 1157h, designated as the holotype of $R$. dehirensis, could not be reexamined, but according to its description by Chauvel and Régnault (1986), it seems to show morphological characteristics of $R$. destombesi. Only the proximal portion of the adoral part of its theca is figured; one circlet of small secondary plates is present between infralaterals and laterals; and according to the description of the authors, the plates do not exhibit any ornamentation.

The presence of small additional intercalary plates was the main argument used by Chauvel and Régnault (1986) to justify the erection of a distinct species (R. dehirensis). This feature is related to intraspecific variability (see the preceding), and consequently, $R$. dehirensis is here considered as a junior synonym of $R$. destombesi.

\section{Rhopalocystis fraga Chauvel, 1971 \\ Figures 5.13, 9.1-9.4, 10.2, 10.4}

1971 Rhopalocystis fraga Chauvel, p. 43, pl. 1, figs. 7, 8; pl. 2, fig. 3.

1971 Rhopalocystis sp.; Chauvel, p. 44, pl. 1 figs. 9, 10.

1978 Rhopalocystis fraga; Chauvel, p. 54, text-fig. $11 \mathrm{~m}$.

1978 Rhopalocystis sp. A; Chauvel, p. 54.

1978 Rhopalocystis sp. B; Chauvel, p. 54, text-fig. 11q.

1986 Rhopalocystis fraga; Chauvel and Régnault, p. 870.

1986 Rhopalocystis sp. A; Chauvel and Régnault, p. 870.

1986 Rhopalocystis sp. B; Chauvel and Régnault, p. 870.

Holotype.-Specimen 1773a from the Fezouata Shale, Agdz area (locality 1773; Fig. 1), Anti-Atlas, Morocco (Chauvel, 1971, pl., 1 fig. 8 ; pl. 2, fig. 3).
Diagnosis.—Rhopalocystis with a small, stocky, strawberryshaped theca, composed of six circlets of plates, one basal plate, one circlet of infralaterals (four plates), one circlet of laterals (six plates), three circlets of radials (columns of three plates). Basal wider than high; thecal plates convex, with facultative small ornamentation folds (granulations).

Occurrence.-Late Tremadocian (A. murrayi Zone), Fezouata Shale, Agdz-Zagora area (localities $809=1157=1725,1773$; Fig. 3) central Anti-Atlas (Morocco).

Description.-The new localities did not yield additional material of $R$. fraga, but a part of the historical material was reexamined. The morphology of the observed specimens corresponds to the descriptions given by Chauvel $(1971,1978)$.

$R$. fraga has a small and stocky strawberry-shaped theca composed of six joined and well-organized circlets of plates (e.g., Fig. 9.1, 9.2). The basal is higher than wide (e.g., Figs. 9.1-9.4, 10.2), and the laterals can also be higher than wide (holotype 1773a; Figs. 9.4, 10.2). The specimens 1725d' and g', not figured by Chauvel $(1971,1978)$, are here illustrated (Fig. 9.1, 9.2). The thecal length of $R$. fraga varies from 1.2 to $1.7 \mathrm{~cm}$. The relief of the plates is very little pronounced; the radials are only slightly convex; the other thecal plates are relatively flat. So far, the brachioles and the stem have never been observed.

Chauvel (1971) mentioned that the thecal plates of R. fraga are covered with small granulations comparable to those of $R$. grandis. This ornamentation was only observed in the specimen 1773a (Fig. 10.2, 10.4). These granulations are smaller and less regular than those of $R$. grandis and can form small vermiculated ornamentation folds on some plates (e.g., laterals, Fig. 10.2, 10.4) more comparable to the ornamentation of $R$. zagoraensis. It is however difficult to determine whether the thecal plates of the other reexamined specimens $(1725 \mathrm{~d}$ ' and $\mathrm{g}^{\prime}$ ) were originally smooth or whether this simply results from the poor state of preservation of the examined latex casts, which were made more than 40 years ago.

Materials.-The original samples could not be reexamined. The observed material comprises latex casts of three original specimens of Chauvel (1971, 1978): one from locality 1773 (Fig. 1), showing three individuals (the holotype 1773a and the two paratypes 1773b, 1773c), and two from locality 809 $(=1157=1725$; Fig. 1$):$ 1725d' and1725g', showing several molds of thecae and numerous isolated basal plates.

Remarks.-The material left in open nomenclature (Rhopalocystis sp. A and sp. B) by Chauvel $(1971,1978)$ could not be directly reexamined. However, as the corresponding specimens

Figure 8. Rhopalocystis destombesi, photographs of latex casts dusted with ammonium chloride. (1) ML 20.268.381b; (2) 2367b1; (3) 2367 SR1; (4) 2367a1; (5) 2367 SR5; (6) 2367 SR6; (7) three specimens, 1157q1 (right side), 1157q2 (middle), and 1157q3 (left side); (8) two partially preserved thecae showing proximal parts of brachioles still in connection with the theca; the specimen $2367 \mathrm{i}$ (right side) is particularly large; (9) two specimens (1750a, b) with a theca almost entirely preserved (only the basal is missing); long parts of brachioles are preserved in connection with the theca; the brachioles of the specimen 1750a (left side) are remarkably well preserved: they seem to be at least twice as long as the theca, but certainly more because their distal extremities are missing; (10) two specimens, $1157 \mathrm{e} 1$ (right side) and $1157 \mathrm{e} 2$ (left side), exhibiting nipple-shaped umbos located in the middle of their plates; they are particularly pronounced in the specimen 1157e1. (1) Locality Z-F25, middle Floian (?B. jacksoni Zone); (2-6, 8) locality 2367, late Tremadocian (H. copiosus Zone); (7, 10) locality 809 $(=1157=1725)$, late Tremadocian $($ A. murrayi Zone $) ;(9)$ locality $1750(=1737=1738)$, late Tremadocian $($ A. murrayi Zone $)$. Scale bars $=1 \mathrm{~cm}$. 

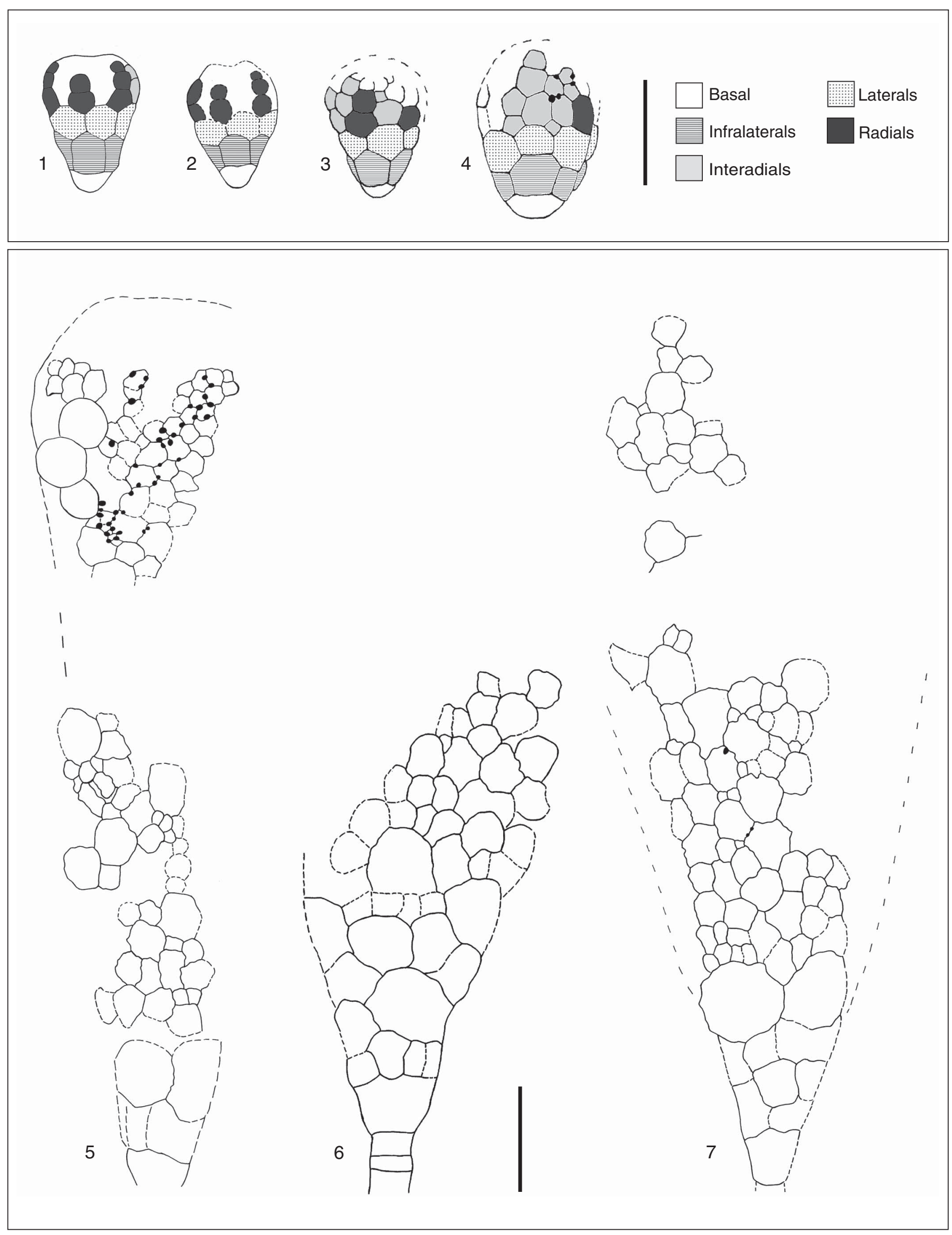


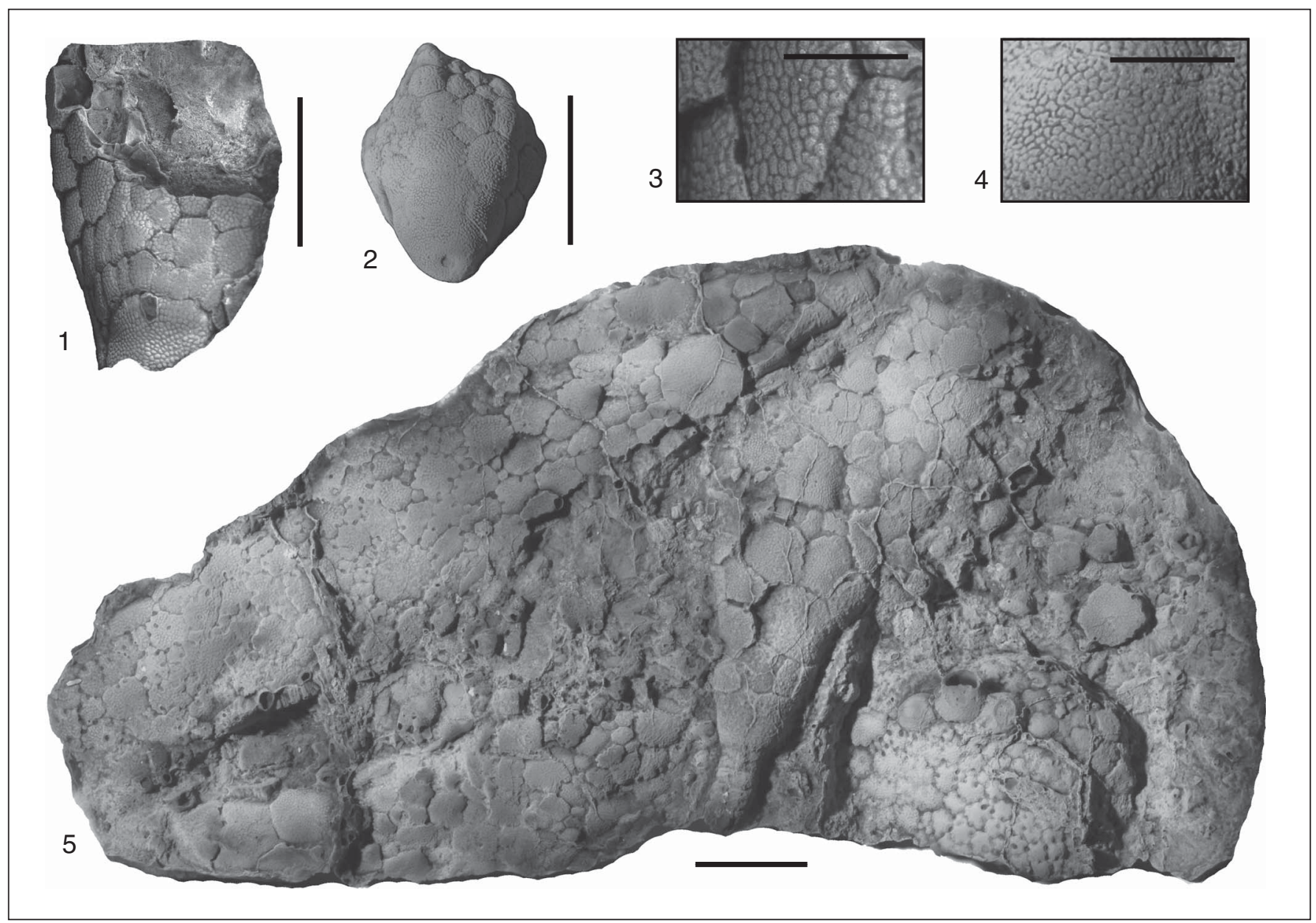

Figure 10. (1, 3-5) Rhopalocystis grandis, photographs of latex casts dusted with ammonium chloride. (1, 3) AA-TISa-OI-5, fragment of theca corresponding to a part of the lateral area, showing the ornamentation diagnostic of $R$. grandis (plate surfaces covered with granulations); locality Z-F12, late Tremadocian (A. murrayi Zone). (5) Three specimens: 1725a (holotype, specimen reversed horizontally at the bottom of the picture), a radius composed of three globular radials can be observed; $1725 \mathrm{~b}$ (left side) theca partially complete; and 1725c (in the center) - the proximal part of its stem and its basal are above the theca of 1725a; locality 809 (=1157 = 1725), late Tremadocian (A. murrayi Zone). $(\mathbf{2}, \mathbf{4}) R$. fraga, photographs of the holotype (1773a), latex casts dusted with ammonium chloride; locality 1773 (Agdz area), Lower Ordovician. Theca entirely preserved; all thecal plates are covered with small granulations that might correspond to ornamentation folds. $(\mathbf{1}, \mathbf{2}, \mathbf{5})$ Scale bars $=1 \mathrm{~cm} ;(\mathbf{3}, \mathbf{4})$ scale bars $=2.5 \mathrm{~mm}$.

were figured (R. sp. A, specimens 1737a, b, Chauvel, 1971, pl. 2, figs. 9, 10; R. sp. B, specimen 1738c, Chauvel, 1978, pl. 3, fig. 11q), they could be compared.

The general shape of the two specimens assigned to Rhopalocystis sp. A is similar to that of R. fraga, but their thecae are smaller and are composed of a smaller number of plates. This suggests that the two specimens assigned to Rhopalocystis sp. A probably correspond to juvenile individuals of $R$. fraga.

The specimens attributed to $R$. sp. B consist of external molds of poorly preserved $R$. fraga-like thecae. Although their state of preservation does not make it possible to observe all diagnostic characters of $R$. fraga, it seems reasonable to assign all specimens of $R$. sp. B to this species.
To avoid an overestimation of the intrageneric richness, both species $R$. sp. A and $R$. sp. B are thus identified here as junior synonyms of $R$. fraga, pending confirmation (or not) of this assignment by new discoveries. The diagnosis of $R$. fraga was thus slightly emended to clearly highlight the main morphological characteristic of this species.

\section{Rhopalocystis grandis Chauvel, 1971}

Figures 5.1, 5.15, 9.5-9.7, 10.1, 10.3, 10.5

1971 Rhopalocystis grandis Chauvel, p. 44, pl. 1, figs. 1-5; pl. 2, fig. 1.

1986 Rhopalocystis grandis Chauvel and Régnault, p. 870.

\footnotetext{
Figure 9. (1-4) Rhopalocystis fraga, small strawberry-shaped thecae partially complete; drawings realized under a stereomicroscope with a camera lucida. (1) 1725g'1; (2) 1725d'1; (3) 1773b; (4) 1773a (holotype). (1, 2) locality $809(=1157=1725)$, late Tremadocian $($ A. murrayi Zone); $(\mathbf{3}, \mathbf{4})$ drawings modified from Chauvel (1971, pl. 1, figs. 7, 8), locality 1773 (Agdz area), Lower Ordovician. (5-7) R. grandis, locality 809 (=1157 = 1725), late Tremadocian (A. murrayi Zone), drawings realized under a stereomicroscope with a camera lucida. (5) 1725a (holotype), large theca almost entirely preserved; a radius composed of three radials is visible; numerous epispires can be observed in the interradial area; (6) 1725c, adoral fragment of theca; few proximal columnals are conserved in connection with theca; (7) 1725b, large theca composed of numerous irregular plates; the aboral part is poorly preserved. Scale bars $=1 \mathrm{~cm}$.
} 
Holotype.-Specimen 1725a from the Fezouata Shale, Zagora area (locality $809=1157=1725$; Fig.1), Anti-Atlas, Morocco (Chauvel, 1971, pl. 2, fig. 1a).

Diagnosis.—Rhopalocystis with a large-sized theca, made up of one basal, numerous irregular plates (infralateral and lateral areas undifferentiated), and three circlets of globular-shaped radials. Thecal plates ornamented with small punctiform granulations.

Occurrence.-Late Tremadocian (A. murrayi Zone), Fezouata Shale, Zagora area (localities $809=1157=1725$, Z-F12c; Fig. 3), central Anti-Atlas (Morocco).

Description. $-R$. grandis is a large-sized species with a long theca composed of one basal plate followed by one large area made of many irregular plates (the infralateral and the lateral areas are not differentiated) and three circlets of radials. Each perradial area is composed of one column of three globular-shaped radial plates; the interradial areas consist of many small irregular plates. The thecal length of $R$. grandis can reach up to $90 \mathrm{~mm}$.

Three of the six specimens originally identified as $R$. grandis by Chauvel (1971) were reexamined (1725a-c; Figs. 9.5-9.7, 10.5). The thecae of specimens $1725 \mathrm{a}$ and $1725 \mathrm{~b}$ are relatively well preserved. They are composed of numerous plates irregular in size and shape. The holotype (1725a; Figs. 9.5, 10.5) shows a well-preserved radius. Three globularshaped radial plates (almost hemispherical) are visible, and the small irregular plates of the interradial area show numerous epispires. The specimen 1725c (Figs. 9.6, 10.5) corresponds to the aboral part of a theca, also composed of irregular plates; the proximal part of the stem is preserved in connection with the theca, and few cylindrical columnals of different sizes can be observed.

Although their shape and size are irregular, the plates of the infralateral and lateral areas exhibit a characteristic pattern resulting from a growth mode by intercalation of new plates (Sprinkle and Guensburg, 2001). These particular successions of plates were already observed by Chauvel (1971), who identified the same plate pattern (P-i2-i1-i2-P) as in some other blastozoans. The large ' $\mathrm{P}$ ' elements correspond to the primary plates (forming the initial transversal circlets of the theca). Intercalary plates 'i1' represent the secondary plates (mediumsized elements) that develop around the primary plates $(\mathrm{P})$. Intercalary plates ' $\mathrm{i} 2$ ' correspond to tertiary plates (smallest elements) that form between primary and secondary plates. This type of growth pattern is visible in the four studied specimens (1725a-c, AA-TISa-OI-5a; Figs. 9.5-9.7, 10.1, 10.5).

Only one new specimen of $R$. grandis was collected during the last excursions in the Zagora area (AA-TISa-OI-5a, from the locality Z-F12c; Fig. 1). This specimen corresponds to a small fragment of theca, composed of a piece of a large plate with a rounded edge, and many other small irregular plates (Fig. 10.1). The thecal plates of $R$. grandis are ornamented with small punctiform granulations. This characteristic ornamentation, already mentioned by Chauvel (1971), is clearly visible in AA-TISa-OI-5a (Fig. 10.1, 10.3).

Materials.-One latex cast from locality 809 (=1157 = 1725; Fig. 1) containing three incomplete external molds of thecae: the holotype (1725a) and two paratypes $(1725 \mathrm{~b}, \mathrm{c})$. One original sample from locality Z-F12c (Fig. 1) showing the partial external mold of a theca: AA-TISa-OI-5a.

Remarks.-Three specimens (1725d-f), originally figured by Chauvel (1971, pl. 2, fig. 1b) could not be reexamined. They consist of several fragments of thecae with incomplete stems and brachioles. However, Chauvel (1971) indicated that their stem was long and flexible and consisted of an irregular alternation of cylindrical, more or less long, distally tapering columnals, as in $R$. destombesi. In these three figured specimens, the brachioles of $R$. grandis appear to be biserial and swollen at the base, also like those of $R$. destombesi (Chauvel, 1971, pl. 2, fig. 1b). The oral surface, the peristomial area, and the periproct (posterior interradial area) have not been observed. The diagnosis was here modified to better specify the main characteristics of this species.

According to the present state of knowledge, the morphology of $R$. grandis appears clearly distinct from that of all other species of Rhopalocystis. However, it cannot be excluded that future discoveries will make it possible to show that $R$. grandis might actually correspond to very large specimens belonging to another species.

\section{Rhopalocystis havliceki Chauvel, 1978 \\ Figures 4.4, 4.6, 5.2, 5.16, 11-13}

1978 Rhopalocystis havliceki Chauvel, p. 55, pl. 5, figs. 2, 3, text-fig. 11f-1.

1978 Rhopalocystis sp. C; Chauvel, p. 55, pl. 5, fig. 4, text-fig. $11 \mathrm{o}-\mathrm{p}$.

1986 Rhopalocystis havliceki; Chauvel and Régnault, p. 870.

1986 Rhopalocystis sp. C; Chauvel and Régnault, p. 870.

2015 Rhopalocystis havliceki; Allaire et al., p. 24, textfig. 2I, J.

2016b Rhopalocystis havliceki; Lefebvre et al., p. 10, textfig. 8A, C.

Holotype.-Specimen $1725 \mathrm{~h} 4.5$ from the Fezouata Shale, Zagora area, locality $809(=1157=1725$; Fig. 1$)$, central AntiAtlas, Morocco (Chauvel, 1978, text-fig. 11f-1).

Diagnosis.-Rhopalocystis with a large-sized theca, composed of one basal, one circlet of infralaterals (four plates) exhibiting one to three, more or less sharp protuberances (umbo); numerous laterals that can have a spine-shaped umbo; usually three circlets of radials (the first and the second radials are elongate and spine-shaped; the third radial is convex).

Occurrence.-Late Tremadocian (A.murrayi Zone), Fezouata Shale, Zagora area (localities $809=1157=1725$, Z-F1, Z-F12c; Fig. 3), central Anti-Atlas (Morocco).

Description.- $R$. havliceki has a large-sized theca (Figs. 11-13), varying in length from 35 to $65 \mathrm{~mm}$. Its thecal width increases slightly but regularly from the proximal to the distal region. The theca of $R$. havliceki is composed of a basal plate, four infralaterals forming one circlet, a lateral area consisting of many plates with irregular shapes and sizes, and three circlets of radials. Each perradial area consists of one column of three 


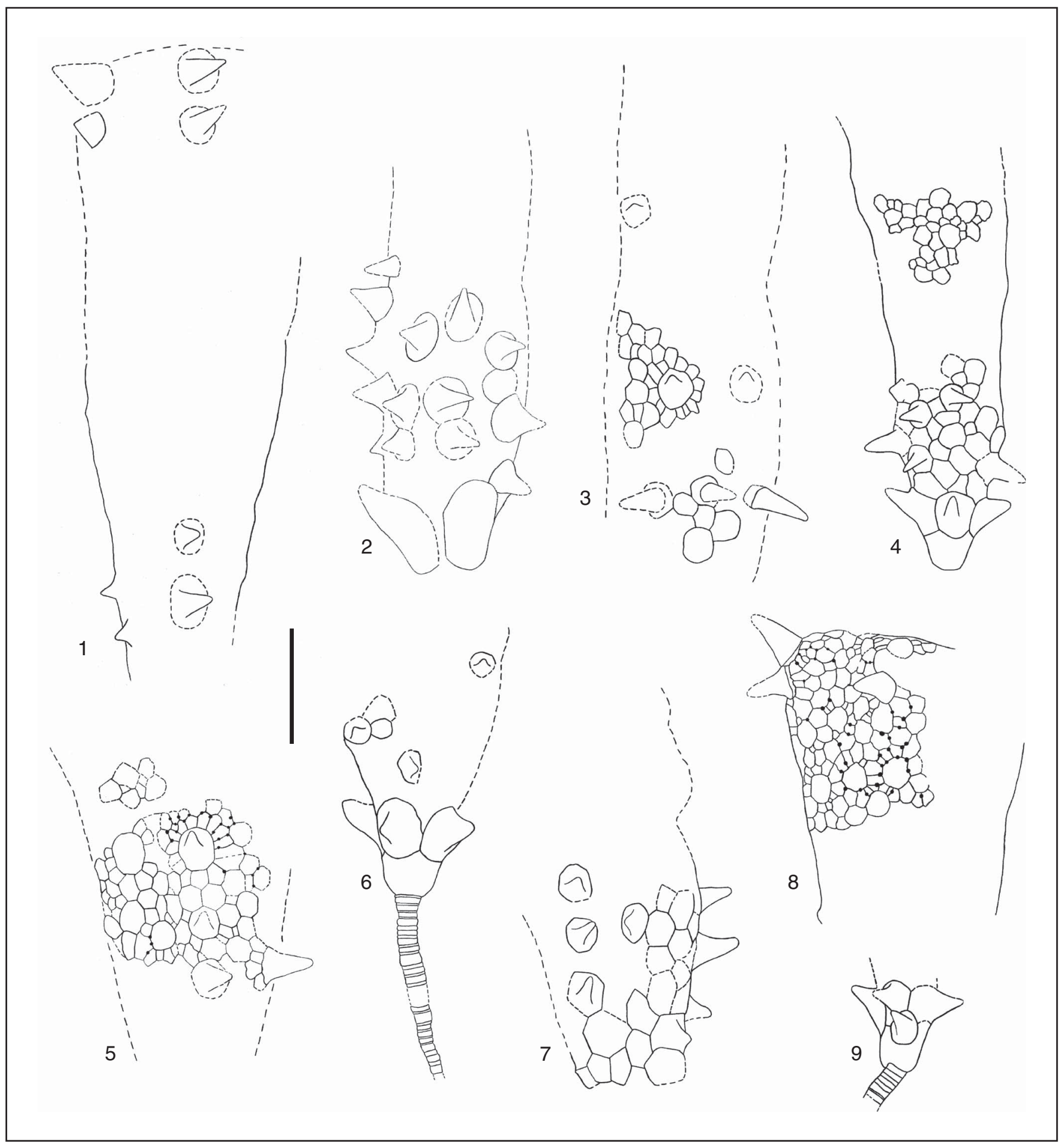

Figure 11. Rhopalocystis havliceki from the locality Z-F1, late Tremadocian (A. murrayi Zone), drawings realized under a stereomicroscope with a camera lucida. (1) AA-TAM-OI-22; (2) AA-TAM-OI-9; (3) AA-TAM-OI-67; (4) AA-TAM-OI-21a; (5) AA-TAM-OI-79; (6) AA-TAM-OI-78b; (7) AA-TAM-OI-73; (8) AA-TAMOI-7; (9) AA-TAM-OI-11. (1-5, 7) Large partially complete thecae, infralaterals, and some laterals have spine-shaped protuberances or are totally spine-shaped; (6, 9) adoral part of thecae with proximal part of stem preserved in connection with the theca; the infralaterals are spine-shaped, in (9) their extremities are particularly sharp; (8) aboral part of theca, with two preserved radii; the two first radials are spine-shaped; the third one is convex. Scale bar $=1 \mathrm{~cm}$.

radials; interradial areas are composed of numerous irregular plates with many epispires.

$R$. havliceki is characterized by a very particular ornamentation. Infralaterals are bearing one, two, or three more or less sharp protuberances (umbos). The plates located in the lower part of the lateral area can have a spine-shaped umbo (length $\sim 3-5 \mathrm{~mm}$ ). The two first radials are entirely spineshaped; the first one is shorter than the second one; the third radial is usually simply convex or exhibits a small umbo (e.g., Figs. 11.1, 11.8, 12.1-12.4, 13.1, 13.3). In one specimen, 


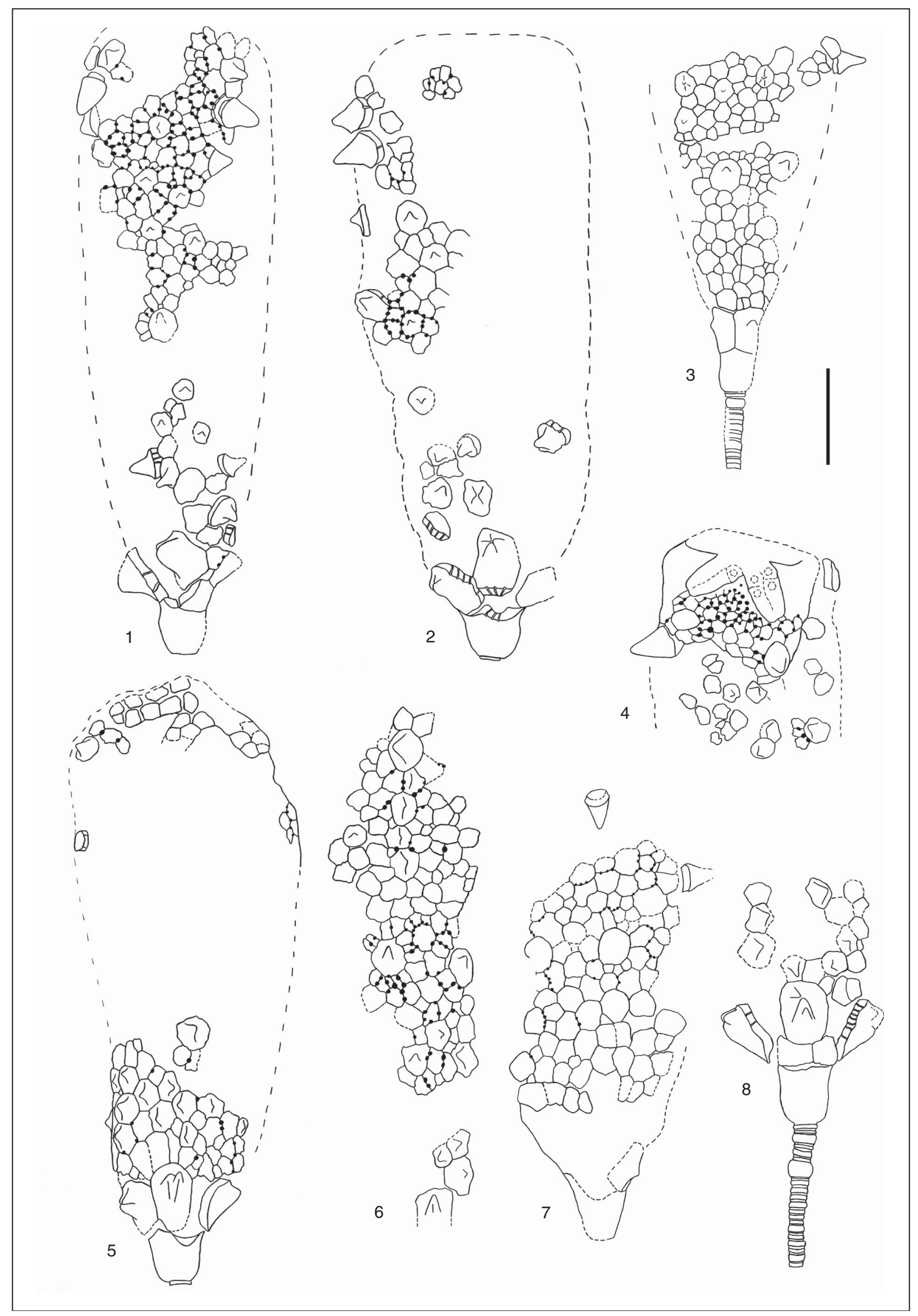


the second radial plate is split in two elements forming two spines (Fig. 12.6).

As far as plate ornamentation is concerned, Chauvel (1971) pointed out the presence of continuous longitudinal ridges on infralateral and lateral plates. These ridges correspond to ornamentation folds and were observed in several specimens (e.g., Fig. 13.4 13.7). In specimen AA-TISa-OI-27a (Fig. 13.4), which corresponds to a partially preserved theca (aboral part missing), all plates exhibit ornamentation folds, some of which are continuous on several plates. The stem and the basal of some specimens also possess this type of folds, which form continuous ridges from the stem to the infralaterals (e.g., Fig. 13.5-13.7). Some specimens do not show this kind of ornamentation (e.g., Fig. 13.8-13.10), but this absence may result from their different preservation (the surfaces of their tests seem to be more weathered).

The proximal part of the stem is preserved in connection with the theca in a few specimens (e.g., Figs. 11.6, 11.9, 12.3, $12.8,13.5-13.7)$. It seems to be made up of cylindrical columnals of various sizes (alternation of short and longer columnals). The longest ones are swollen (nodal-shaped) and can show small longitudinal ridges, which are little pronounced (e.g., Fig. 13.6, 13.7).

As in $R$. grandis, the plates of the lateral area show a characteristic pattern resulting from a growth mode by intercalation of new elements (Sprinkle and Guensburg, 2001; e.g., Figs. 11.3-11.5, 11.8, 12.3, 12.7). The plates exhibiting spine-shaped protuberances seem to be the primary plates $(\mathrm{P})$, which formed the initial organization of the theca into transversal circlets. The secondary plates are smaller, not ornamented, and their shape is more irregular. Therefore, the growth by intercalation of plates seems to begin from a theca constituted of different primary circlets: a basal circlet (one plate), one circlet of infralaterals (four plates), several circlets of spine-shaped laterals, and three circlets of radials.

The morphology of the oral surface of $R$. havliceki (rarely preserved) is comparable to that of $R$. destombesi (e.g., Fig. 7.10). However, the ambulacra seem to be composed of a larger number of plates. According to the specimen AA-TISa-OI-22g (Figs. 12.4, 13.3), the ambulacra of $R$. havliceki seem to be constituted of eight brachioliferous plates, and the oral surface is apparently flattened, in contrast to the situation in other species, which have a more convex oral surface. The posterior interradial area (with the periproct) and the peristomial area have not been observed.

Materials.-Several poorly preserved latex casts of original specimens examined by Chauvel (1978), corresponding to external molds of incomplete thecae: 2082a, 2082b (locality 2082; Fig. 1), 1725h4.5 (holotype), and 1725e' (locality
$809=1157=1725 ;$ Fig. 1). Numerous original samples containing about 100 external molds of thecae, coming from the localities Z-F1 (AA.TAM.OI.1-80) and Z-F12c (AA.TISa. OI.22, 23, AA.TISa.OI.25-27) (Fig.1).

Remarks.-The species Rhopalocystis C, left in open nomenclature by Chauvel (1978, text-fig. 11o, p), was created for only one specimen (2082a) coming from locality 2082. This specimen corresponds to a fragmentary theca, with only the lateral area preserved. However, the presence of spine-shaped protuberances on several plates is a diagnostic feature of $R$. havliceki. Therefore, $R$. sp. C is here identified as a junior synonym of $R$. havliceki.

As far as the ornamentation of $R$. havliceki is concerned, some differences can be observed between the populations coming from localities Z-F1 and Z-F12c. In specimens from Z-F12c, infralaterals can have one, two, or three rounded protuberances (e.g., Figs. 12.1-12.3, 12.5-12.8, 13.4, 13.5, 13.7), while in specimens from Z-F1, these plates exhibit only one protuberance, which can be elongated and spine-shaped (e.g., Figs. 11.2, 11.4, 11.6, 11.9, 13.8-13.10).

The diagnosis of $R$. havliceki was completed, thanks to the observation of the new material, in order to bring out more accurately the morphological characteristics of this species.

Rhopalocystis zagoraensis Chauvel, 1971

Figures 4.3, 5.3-5.8, 5.12, 5.18-5.20, 14, 15

1971 Rhopalocystis zagoraensis Chauvel, p. 45, pl. 1, fig. 6; pl. 2 fig. 2.

1978 Rhopalocystis zagoraensis; Chauvel, p. 52, fig. 11a-e.

1986 Rhopalocystis lehmani; Chauvel and Régnault, p. 866, pl. 1, figs. 9, 10, text-fig. 3I-N.

1986 Rhopalocystis zagoraensis; Chauvel and Régnault, p. 865, text-fig. 3O; p. 867, specimen M.1725f.

2015 Rhopalocystis zagoraensis; Allaire et al., p. 24, textfig. 2E, G.

2016b Rhopalocystis zagoraensis, Lefebvre et al., p. 10, text-fig. 8B.

Holotype.-Specimen 1725g from the Fezouata Shale, Zagora area, locality $809(=1157=1725$; Fig. 1$)$, Anti-Atlas, Morocco (Chauvel, 1971, pl. 1, fig. 6; pl. 2, fig. 2).

Diagnosis.-Rhopalocystis with a theca composed of six primary circlets of plates, one basal, one circlet of infralaterals (four plates), one circlet of laterals (four to six plates), and three circlets of radials (perradial areas consisting of columns of three plates); additional secondary plates between infralaterals and laterals (up to three circlets of plates), between laterals and

\footnotetext{
Figure 12. Rhopalocystis havliceki from the locality Z-F12c, late Tremadocian (A. murrayi Zone), drawings realized under a stereomicroscope with a camera lucida. (1) AA-TISa-OI-22j; (2) AA-TISa-OI-22h. $(\mathbf{1}, \mathbf{2})$ Large thecae; several spine-shaped radials are preserved; some laterals exhibit a spine-shaped umbo more or less rounded; the infralaterals seem to have several rounded protuberances (three in (2)). (3) AA-TISa-OI-23a, relatively small theca; a radius is partially exposed; the first radial is missing; the second one is spine-shaped; the third one is convex; the infralaterals and the largest laterals have a small umbo. (4) AA-TISa-OI-22g, aboral fragment of theca; a part of the oral surface is preserved; some spine-shaped radials are visible; the ambulacra seem to have eight brachioliferous plates; numerous epispires are located within the interradial area, which has been preserved. (5) AA-TISa-OI-22i, large theca partially complete; some laterals exhibit a small umbo; infralaterals have two or three protuberances; some ambulacra are preserved; they seem constituted of eight brachioliferous plates; a radial with a small umbo can be observed. (6) AA-TISa-OI-22l, large fragment of theca; one radius is partially preserved; the first radial is spine-shaped; the second one seems to be split in two plates also spine-shaped; some laterals exhibit a small protuberance. (7) AA-TISa-OI-22a, theca partially complete; two disconnected radials can be observed; they are spine-shaped. (8) AA-TISa-OI-22e, adoral part of theca with a relatively large portion of stem conserved in connection with the theca; it is constituted of columnals of different sizes; one of them is particularly swollen (nodal-shaped); the infralaterals possess several rounded protuberances, and some laterals have a small umbo. Scale bar $=1 \mathrm{~cm}$.
} 

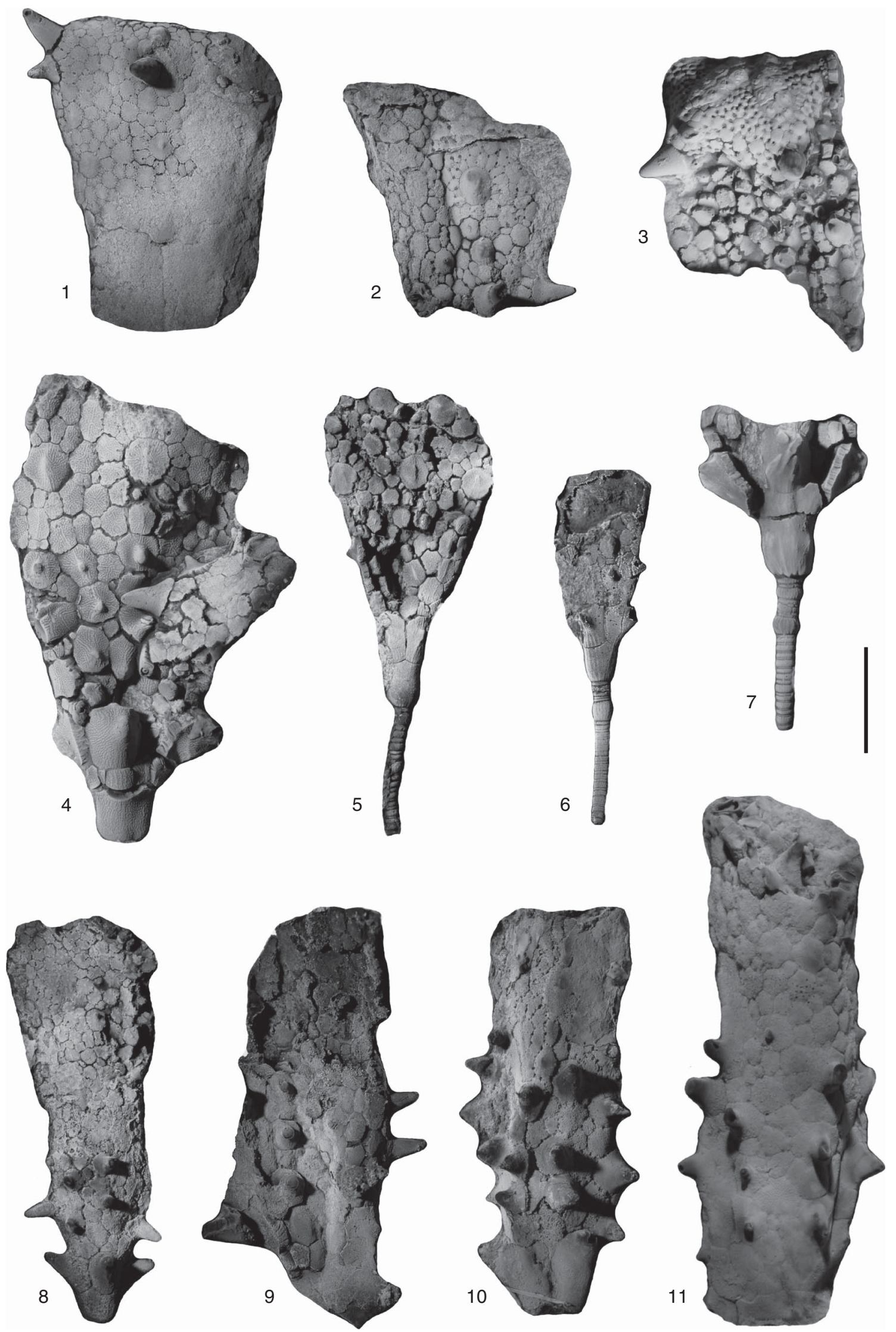
radials (isolated plates or one circlet), and forming sometimes rows between laterals; the basal can be split; radials globularshaped; thecal plates ornamented with continuous vermiculated folds. Stem composed of cylindrical columnals of different sizes, some of them more elongated and nodal-shaped (swollen).

Occurrence.-Late Tremadocian (A. victoriae Zone to $H$. copiosus Zone), Fezouata Shale, Zagora area, localities 809 $(=1157=1725), 2367$, Z-F1, and Z-F12c (Fig. 3), central Anti-Atlas (Morocco).

Description.-The theca of $R$. zagoraensis is relatively small (thecal length between 15 and $21 \mathrm{~mm}$ ). It is made up of six principal circlets of plates. The basal circlet is generally composed of one plate, but this basal plate is sometimes split into two superposed elements (e.g., Figs. 14.19, 14.20, 15.12), which is unique within the genus Rhopalocystis. The infralateral circlet is composed of four plates, and the lateral circlet is composed of a variable number of plates between four and six. The radials are generally organized in three circlets. Numerous additional secondary plates can be intercalated between the six primary circlets of plates. Their shape, size, and organization are irregular. These intercalary plates can be located between infralaterals and laterals (e.g., Fig. 14.1-14.17, 14.19-14.21), and between laterals and radials (e.g., Fig. 14.1-14.4, 14.6-14.8, 14.10, 14.11, 14.13, 14.14). Some specimens also display additional rows of plates between laterals (e.g., Fig. $14.1-14.3,14.8,14.10,14.11,14.14)$. The additional skeletal elements located between infralaterals and laterals can be very numerous and form up to three circlets of plates. Usually, the additional plates located between laterals and radials are less numerous; they can consist of isolated plates or form one complete circlet. The size, shape, and organization of these secondary plates are irregular, and they do not form continuous and well-defined circlets, but rather an irregular, disorganized pavement.

The radials have a characteristic globular shape (almost hemispheric) and usually constitute three circlets (e.g., Fig. 14.1-14.13, 14.15, 14.17, 14.20), but some individuals have four circlets of radials (e.g., Fig. 14.14), and some small specimens seem to have only two radial circlets (e.g., Fig. 14.18, 14.21) .

R. zagoraensis is characterized by a typical ornamentation, already described by Chauvel $(1971,1978)$ and consisting of continuous folds (Fig. 15). Indeed, thecal plates are ornamented with vermiculated ridges (folds), but this ornamentation is more or less pronounced among the individuals. In some specimens, the plates have only short vermiculated folds, whereas in others, the thecal plates have both small and long folds, which are continuous on several plates and meet at the center of the largest ones (infralaterals, laterals). This produces a characteristic pattern corresponding to vermiculate radiating ridges (Fig. $15.1-15.3,15.5,15.10,15.14)$. Usually the radials also have ornamentation folds. Finally, in some specimens, this typical ornamentation (small vermiculated folds) is little pronounced (e.g., Fig. 15.4, 15.6-15.9, 15.12, 15.13, 15.15), and sometimes only the basal is vermiculated (e.g., Fig. 15.13). The extension and strength of the ornamentation are highly variable among individuals. This variability in the ornamentation can be observed at each locality. Plate boundaries can be bordered by numerous epispires, and they are sometimes difficult to identify in the most ornamented specimens because of the vermiculated ridges (e.g., Fig. 15.2, 15.4, 15.5, 15.8, 15.10, 15.14).

In some specimens, the proximal part of the stem is preserved in connection with the theca (e.g., Figs. 14.5, 14.6, $14.13,15.7,15.11,15.12)$. It is made up of cylindrical columnals of various sizes; some of them are more elongated, swollen, and nodal-shaped.

Apart from the globular shape of the radials, the morphology of the oral surface of $R$. zagoraensis (e.g., Figs. 14.22, 15.16) is very similar to that of $R$. destombesi. The posterior interradial area can be observed in several specimens (e.g., Figs. 14.3, 14.4, 14.8-14.10, 14.12, 14.18, $14.20,14.22,15.4,15.5,15.9,15.13,15.15,15.16)$; the organization of this area appears to be also comparable to that of $R$. destombesi. It is composed of a higher number of plates comparing with the other interradii, and the periproct is located at the same place, behind the anal protuberance (a plate with an important relief). The brachioles were not observed, but they are probably biserial and swollen at their base.

Materials.-Several latex casts of the original study material of Chauvel (1971, 1978) and Chauvel and Régnault (1986): the holotype $1725 \mathrm{~g}$ and $1725 \mathrm{~b}^{\prime}, \mathrm{c}^{\prime} 1, \mathrm{f}^{\prime}, \mathrm{h}, \mathrm{h}$ ', i1, i3, i6-i8, i12, i16, i17, i19, j6-j8 (locality $809=1157=1725$; Fig. 1) and 2367c1, c2, c3, d1, d2 (locality 2367; Fig. 1).

Examined original samples include specimens $1725 \mathrm{~h}^{\prime}$ (locality $809=1157=1725$; Fig. 1), 2367c and d (locality 2367; Fig. 1), as well as numerous external molds of thecae from Z-F12c (Fig. 1): AA-TISa-OI-1-24 and UCBL-FSL 712.044.

Two original samples with external molds of thecae and isolated plates, coming from locality Z-F1 (Fig. 1): AA-TAMOI-64 and 74.

Remarks.-In R. zagoraensis, the variability in the number of additional plates appears to reflect a growth allometry. Indeed,

Figure 13. Rhopalocystis havliceki, photographs of latex casts dusted with ammonium chloride. (1, 2, 6, 8-10) Locality Z-F1, late Tremadocian; (3-5, 7) locality Z-F12c; late Tremadocian (A. murrayi Zone); (11) locality 2082, Lower Ordovician. (1) Aboral part of theca, two radii are visible (AA-TAM-OI-7). (2) Fragment of a theca (lateral area), with both extremities missing (AA-TAM-OI-79). (3) Aboral part of theca; a part of the oral surface is preserved; two ambulacra are visible; each possesses eight brachioliferous plates (AA-TISa-OI-22g). (4) Theca with the aboral part missing; the ornamentation is clearly visible; some plates exhibit a central umbo; all plates possess small ornamentation folds that can be continuous from plate to plate (AA-TISa-OI-27a); an aboral fragment of theca belonging to another individual (AA-TISa-OI-27b, right side) is preserved above the theca of AA-TISa-OI-27a; two spine-shaped radials are visible. (5) AA-TISa-OI-26; (6) AA-TAM-OI-6a; (7) AA-TISa-OI-22e; (5-7) adoral part of thecae with the proximal part of stem preserved in connection with theca. (8) AA-TAM-OI-21a; (9) AA-TAM-OI-22; (10) AA-TAM-OI-9; (11) 2082a (specimen initially assigned to Rhopalocystis sp. C and figured by Chauvel, 1978, text-fig. 11o, p, pl. 5 fig. 4); (8-11) thecae partially complete; the aboral part is missing; the spine shape of some laterals is clearly visible; these plates seem particularly robust. Scale bar $=1 \mathrm{~cm}$. 

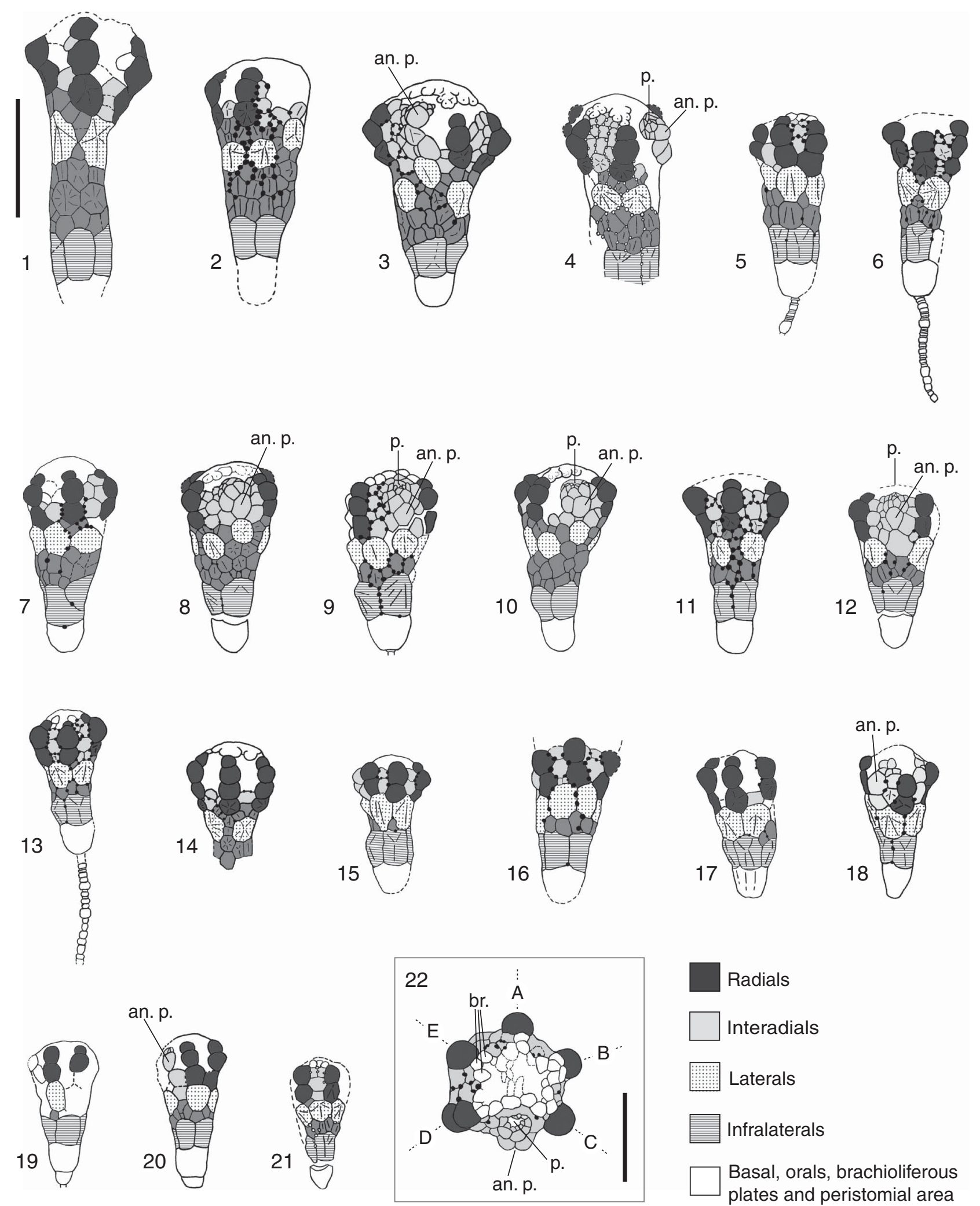
specimens possessing several circlets of intercalary plates are usually the largest ones (e.g., Figs. 14.1-14.4, 15.1-15.5). It nevertheless appears difficult to establish a general rule because some small specimens already possess several additional plates, while some larger specimens do not have secondary plates (e.g., compare Fig. 14.18, 14.21).

The first additional secondary plates can appear between infralaterals and laterals or between laterals and radials. Indeed, they seem to occur anywhere and completely randomly (unconstrained growth). The number and organization of additional plates vary widely from one individual to another. Comparing the largest specimens of $R$. zagoraensis, which usually correspond to the specimens with the highest number of additional plates, it appears that the organization of these elements and the conformation of the theca are highly variable from one specimen to another, even if all have a subequal number of intercalary plates (e.g., Figs. 14.1-14.4, 15.1-15.5).

As in $R$. destombesi, the thecal growth in $R$. zagoraensis seems to result both from a simple holoperipheric growth of the plates forming the six primary circlets (this organization is probably fixed at an early ontogenetic stage) and by the insertion of secondary plates intercalated between some of these six main circlets. The holotype (1725g; Figs. 14.1, 15.1) exhibits the typical organization 'P-i2-i1-i2-P' resulting from a growth mode by intercalation of new plates (Sprinkle and Guensburg, 2001).

The particular ornamentation of $R$. zagoraensis is very similar to that described in some primitive rhombiferan glyptocystitids, such as Macrocystella bohemica (Barrande, 1887). It consists of folds (ridges), which are continuous from one plate to another and can join at the center of the largest plates, thus forming a characteristic pattern (vermiculated radiating ridges). In $R$. zagoraensis, this type of ornamentation seems to change during the growth. In the early stages of the development, before the appearance of intercalary plates, the plates of the six primary circlets of the theca seem to exhibit only discontinuous small vermiculate folds. Then, some of these small ridges become progressively longer to form continuous lines, joining at the center of the largest plates. However, considering individuals of the same size, ornamentation intensity appears relatively variable, with some specimens having a strong ornamentation (e.g., Fig. 15.2, 15.3, 15.5, 15.10, 15.14), while some others from the same locality having a much reduced ornamentation (e.g., Fig. 15.6, 15.7, 15.9, 15.11, 15.12). The significant variations observed in the plate pattern and the ornamentation of the theca illustrate the strong intraspecific morphological variability (important polymorphism) that characterizes the species $R$. zagoraensis.
In the specimen $1725 \mathrm{~g}$ (Figs. 14.1, 15.1), originally designated as the holotype of $R$. zagoraensis (Chauvel, 1971), the theca is made up of six principal circlets of plates and numerous additional plates, intercalated between infralaterals and laterals (three circlets showing the structure 'P-i2-i1-i2-P') and between laterals and radials (incomplete circlet). The plates are ornamented with vermiculated radiating folds. The radials are rather globular, even if the presence of ornamentation folds tends to give them a conical shape.

Among the specimens identified as R. lehmani by Chauvel and Régnault (1986, text-fig. 3I-N), two could be reexamined (2367c1, 1725i16). The specimen 2367c1 (Fig. 21.8; Chauvel and Régnault, 1986, text-fig. 3I) possesses all the diagnostic features of $R$. zagoraensis: a theca composed of six primary circlets of plates with numerous additional secondary plates, globular-shaped radial plates, and vermiculated ornamentation folds. The theca of the specimen $1725 \mathrm{i} 16$ is not entirely preserved (Chauvel and Régnault, 1986, text-fig. 3M), and its ornamentation cannot be observed because of the poor state of the latex cast. However, numerous irregular additional secondary plates are visible between infralaterals and laterals: this morphological feature is typical of $R$. zagoraensis. Thus, the specimens $2367 \mathrm{cl}$ and $1725 \mathrm{i} 16$ are here identified as $R$. zagoraensis. The other specimens assigned to $R$. lehmani (1725c1, 2367g4, 1725i15, j4; see Chauvel and Régnault, 1986, text-fig. 3J-L, N) seem also to belong to $R$. zagoraensis. The holotype of $R$. lehmani (1725j4) was initially assigned to $R$. zagoraensis by Chauvel (1978, text-fig. 11a) and was subsequently identified as $R$. lehmani by Chauvel and Régnault (1986, text-fig. 3N). According to the original illustrations of Chauvel (1978) and Chauvel and Régnault (1986), this specimen shows numerous additional intercalary plates between infralaterals and laterals; their shape and size are irregular; and they do not constitute well-organized circlets. Chauvel (1978) mentioned that its thecal plates were covered by continuous ornamentation folds forming a radiating pattern. Moreover, the radials are globular (almost hemispheric), and the basal plate is split into two elements. The globular-shaped radials, the ornamentation folds, the numerous intercalary plates, and the split basal all confirm that this specimen can be assigned to $R$. zagoraensis. The specimens $1725 \mathrm{c} 1,2367 \mathrm{~g} 4$, and $1725 \mathrm{i} 15$ (Chauvel and Régnault, 1986, text-fig. 3J-L) correspond to incomplete, aboral portions of thecae. Their ornamentation was not illustrated, but they show numerous irregular additional plates between infralaterals and laterals; the radial plates of specimen $2367 \mathrm{~g} 4$ seem to be globular. Therefore, it seems reasonable to assign these specimens to $R$. zagoraensis.

\footnotetext{
Figure 14. Rhopalocystis zagoraensis, drawings realized under a stereomicroscope with a camera lucida. (1) Holotype (1725g), figured by Chauvel (1971, pl. 1 fig. 6, pl. 2 fig. 2) and Chauvel and Régnault (1986, text-fig. 3O); (2) UCBL-FSL 712.044b; (3) 2367c3; (4) AA-TISa-OI-17a; (5) AA-TISa-OI-21c; (6) 2367d2; (7) AA-TISa-OI-13a; (8) 2367c1; (9) AA-TISa-OI-16a, theca without additional secondary plates, constituted of five circlets of plates (one basal, one infralateral, one lateral, and two radial circlets); (10) 1725h'; (11) 2367d1; (12) AA-TISa-OI- 12a; (13) AA-TISa-OI-21a; (14) 2367c2; (15) AA-TISa-OI-21b; (16) AA-TISa-OI-11a; (17) AA-TISa-OI-20a; (18) AA-TISa-OI-16b; (19) AA-TISa-OI-12b; (20) 1725c'1; (21) AA-TISa-OI-16c; (22) AA-TISa-OI-16d, oral surface of the theca showing globular radials, the five ambulacra, the brachioliferous plates, the peristomial area, and the anal region containing the periproct. $(\mathbf{1 - 5}, \mathbf{7}, \mathbf{8}, \mathbf{1 0})$ Thecae having several circlets of secondary plates between infralaterals and laterals; some additional plates can also be observed between laterals and radials (as isolated elements or forming a complete circlet). $(\mathbf{6 , 9}, \mathbf{1 1 - 1 4 , 2 0 , 2 1}$ ) Thecae with one complete circlet of secondary plates between infralaterals and laterals. $(\mathbf{1 5 - 1 7 , 1 9 )}$ Thecae with additional secondary plates, as isolated elements or forming an incomplete circlet, between infralaterals and radials. (1-3, 8, $\mathbf{1 0}, \mathbf{1 1}, \mathbf{1 4})$ Thecae exhibiting rows of additional secondary plates between laterals. $(\mathbf{3}, \mathbf{4}, \mathbf{8 - 1 0}, \mathbf{1 2}, \mathbf{1 8}, \mathbf{2 0})$ The posterior interradial area can be observed: it is larger than other interradial areas and contains the anal protuberance and the periproct. (19, 20) The basal plate seems to be split in two elements; the smaller one might be considered as a first proximal columnal that would be particularly large. $(\mathbf{1}, \mathbf{1 0})$ Locality $809(=1157=1725)$, late Tremadocian $($ A. murrayi Zone); $(\mathbf{2}, \mathbf{4}, \mathbf{5}, \mathbf{7}, \mathbf{9}, \mathbf{1 2}, \mathbf{1 3}, \mathbf{1 5 - 1 9}, \mathbf{2 1}, \mathbf{2 2})$ locality Z-F12c, late Tremadocian (A. murrayi Zone); $(\mathbf{3}, \mathbf{6}, \mathbf{8}, \mathbf{1 1}, \mathbf{1 4})$ locality 2367, late Tremadocian (H. copiosus Zone). The main ornamentation folds are illustrated. (1-21) Scale bar $=1 \mathrm{~cm} ;(\mathbf{2 2})$ scale bar $=5 \mathrm{~mm}$.
} 


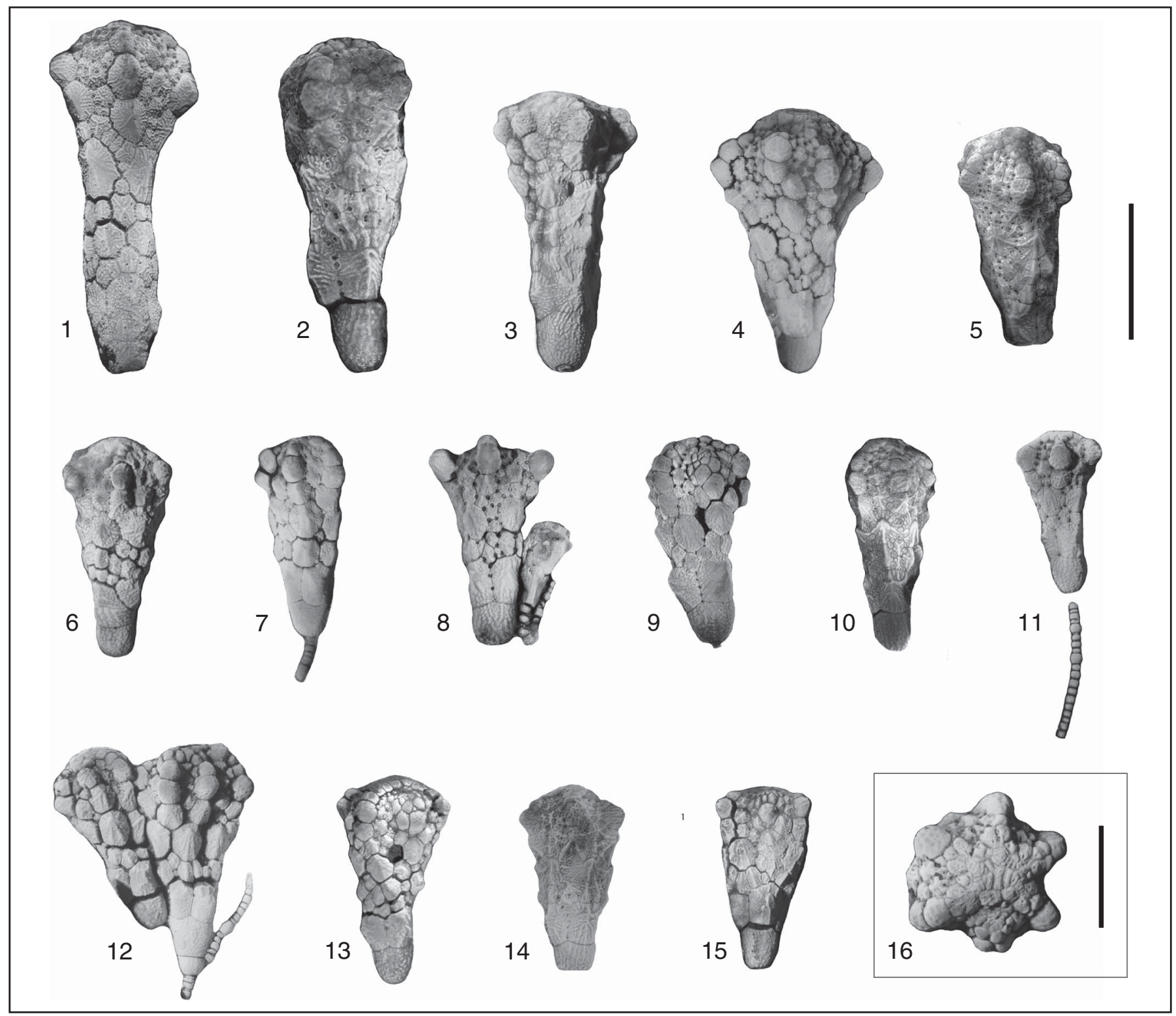

Figure 15. Rhopalocystis zagoraensis, photographs of latex casts dusted with ammonium chloride, thecae particularly well preserved; the characteristic ornamentation folds are clearly visible; this ornamentation can be more or less accentuated; all specimens possess additional secondary platelets in addition to the six primary circlets of plates constituting their theca. (1) Holotype 1725g; (2) AA-TISa-OI-17b; (3) UCBL-FSL 712.044a; (4) 2367c3; (5) AA-TISa-OI-17a; (6) AA-TISa-OI-13a; (7) AA-TISa-OI-21c; (8) 2367d1 (left side) and 2367dE, a small-sized individual, which might correspond to a juvenile of Rhopalocystis sp. (right side); (9) AA-TISa-OI-16a; (10) AA-TISa-OI-17e; (11) AA-TISa-OI-21a; (12) AA-TISa-OI-21d (right side) and AA-TISa-OI-21e (left side); (13) 1725h'; (14) AA-TISa-OI-17d; (15) AA-TISa-OI-12a; (16) AA-TISa-OI-16d, oral surface particularly well preserved, showing the globular-shaped radials, the five ambulacra, the brachioliferous plates, the peristomial area, and the anal region containing the periproct. (1-3, 5, 10, 14) Specimens having a strong ornamentation, consisting of both small and vermiculated, and long and continuous ornamentation folds; the longest ones are joining at the center of the largest plates, producing a characteristic pattern corresponding to vermiculated radiating ridges. $(\mathbf{4}, \mathbf{6 - 9 ,} \mathbf{1 1 - 1 3}, \mathbf{1 5})$ Specimens with a fainter ornamentation, consisting only of small vermiculated folds. $(\mathbf{1}, \mathbf{1 3})$ Locality $809(=1157=1725)$, late Tremadocian $($ A. murrayi Zone $) ;(\mathbf{2}, \mathbf{3}, \mathbf{5}-\mathbf{7}, \mathbf{9 - 1 2}, \mathbf{1 4 - 1 6})$ locality Z-F12c, late Tremadocian (A. murrayi Zone); (4, 8) locality 2367, late Tremadocian (H. copiosus Zone). (1-15) Scale bar = $1 \mathrm{~cm} ;(\mathbf{1 6}) \mathrm{scale}$ bar $=5 \mathrm{~mm}$.

Consequently, the diagnosis of $R$. zagoraensis was emended to clearly specify the main characteristics defining its morphology, which is characterized by an important polymorphism. R. lehmani is here considered as a junior synonym of R. zagoraensis.

\section{Conclusion}

Rhopalocystis is an endemic eocrinoid genus, which has been reported only from Lower Ordovician levels (Fezouata Shale) of the
Agdz-Zagora area, in central Anti-Atlas (Morocco). The stratigraphic distribution of the different Rhopalocystis-dominated observed communities ranges from the middle Tremadocian (A. victoriae Zone) to the middle Floian (?B. jacksoni Zone) (Lefebvre et al., 2016b). This genus initially included ten species: $R$. destombesi (Ubaghs, 1963), R. fraga, $R$. grandis, $R$. zagoraensis, $R$. sp. A (Chauvel, 1971), $R$. havliceki, $R$. sp. B, $R$. sp. C (Chauvel, 1978), R. dehirensis, and R. lehmani (Chauvel and Régnault, 1986).

The detailed examination of both historical samples and the new recently collected material (ANR research project 'Rise of 
Animal Life'), coupled with cladistic and morphometric analyses, made it possible to reassess the morphological variability and thus to propose a critical revision of this genus. Rhopalocystis now appears to be composed of only five morphological species: $R$. destombesi, $R$. fraga, $R$. grandis, $R$. havliceki, and $R$. zagoraensis.

Considering the systematic revisions proposed here, $R$. dehirensis, $R$. lehmani, and the three species left in open nomenclature ( $R$. sp. A, $R$. sp. B, and $R$. sp. C) should be now considered as invalid. The specimens originally identified as $R$. dehirensis (Chauvel and Régnault, 1986) are attributed to $R$. destombesi; those identified as $R$. lehmani (Chauvel and Régnault, 1986) are assigned to $R$. zagoraensis. The specimens corresponding to $R$. sp. A and $R$. sp. B (Chauvel, 1971, 1978) are assigned to $R$. fraga, and $R$. sp. C (Chauvel, 1978) is now identified as $R$. havliceki. The polymorphism of some species, the presence of growth allometry, and more generally the very large morphological disparity characterizing the genus Rhopalocystis probably explain the previously overestimated intrageneric specific richness.

\section{Acknowledgments}

This study was part of the project RALI (Rise of Animal Life), funded by the ANR (Agence Nationale de la Recherche, France; grant number ANR-11-BS56-0025), and part of the CNRSCNRST cooperation program VALORIZ (grant number 52943). The authors are particularly thankful to M. Nohejlová (Charles University, Prague, Czech Republic), B. Deline (University of West Georgia, Carrollton, United States), and I.A. Rahman (University of Oxford, Oxford, England) for reviewing the manuscript and making many helpful remarks. The authors are also grateful to D. Berthet (Musée des Confluences, Lyon, France), K. El Hariri (Université Cadi Ayyad, Marrakesh, Morocco), F.J. Lindemann and H.A. Nakrem (Natural History Museum, Oslo, Norway), J. Plaine (Institut de Géologie, Rennes, France), A. Prieur and E. Robert (Université Lyon 1, Villeurbanne, France), and S. Régnault (Muséum d'Histoire naturelle, Nantes, France) for providing access to specimens and/or latex casts of specimens housed in their collections. Precious field assistance was provided by A. Bachnou and A. Hafid (Marrakesh), B. Pittet and H. Hormière (Villeurbanne), M. Masrour (Agadir), F. Noailles (Bristol), H. Nowak and T. Vandenbroucke (Villeneuve d'Ascq), R. and V. Reboul (Saint-Chinian), M. Vidal (Brest), and D. Vizcaïno (Carcassonne). The authors also thank mad meg, the artist who made the beautiful illustration of Rhopalocystis destombesi (Fig. 2.5).

\section{References}

Akaike, H., 1974, A new look at the statistical model identification: IEEE Transactions on Automatic Control, v. 19, no. 6, p. 716-723.

Allaire, N., Lefebvre, B., Martin, E., Nardin, E., and Vaucher, R., 2015, Taphonomy of new Rhopalocystis assemblages in the Lower Ordovician of the Zagora area (central Anti-Atlas, Morocco), in Zamora, S., and Rabano, I., eds., Progress in Echinoderm Palaeobiology: Cuadernos del Museo Geominero, v. 19, p. 21-26.

Ausich, W.I., Rhenberg, E.C., Kammer, T.W., and Deline, B., 2013, Rooting the early crinoid diversification with the eocrinoid Rhopalocystis: Geological Society of America Abstracts with Programs, v. 45, no. 7, p. 109.
Ausich, W.I., Kammer, T.W., Rhenberg, E.C., and Wright, D.F., 2015, Early phylogeny of crinoids within the pelmatozoan clade: Palaeontology, v. 58, no. 6, p. 937-952.

Barrande, J., 1887, Système Silurien du Centre de la Bohême: Volume VII. Classe des Echinodermes, Ordre des Cystidées: Prague, Rivnac, 233 p.

Broadhead, T.W., 1982, Reappraisal of class Eocrinoidea (Echinodermata), in Lawrence, J.M., ed., Echinoderms, Proceedings of the International Conference, Tampa Bay: Rotterdam, Balkema, pp. 125-131.

Chauvel, J., 1941, Recherche sur les cystoïdes et les carpoïdes armoricains: Mémoires de la Société géologique et minéralogique de Bretagne, v. 5, p. $1-286$.

Chauvel, J., 1971, Rhopalocystis Ubaghs: un échinoderme éocrinoïde du Trémadocien de l'Anti-Atlas marocain: Mémoires du Bureau de Recherches Géologiques et Minières, v. 73, p. 43-49.

Chauvel, J., 1978, Compléments sur les échinodermes du Paléozoïque marocain (diploporites, éocrinoïdes, édrioastéroïdés): Notes et Mémoires du Service géologique du Maroc, v. 272, p. 27-78.

Chauvel, J., and Régnault, S., 1986, Variabilité du genre Rhopalocystis Ubaghs, éocrinoïde du Trémadocien de l'Anti-Atlas marocain: Geobios, v. 19, p. $863-870$

Clausen, S., 2004, New early Cambrian eocrinoids from the Iberian Chains (NE Spain) and their role in nonreefal benthic communities: Eclogae Geologicae Helvetiae, v. 97, no. 3, p. 371-379.

Clavel, J., Merceron, G., and Escarguel, G., 2014, Missing data estimation in morphometrics: How much is too much?: Systematic Biology, v. 63, no. 2, p. 203-218.

Dempster, A.P., Laird, N.M., and Rubin, D.B., 1977, Maximum likelihood from incomplete data via the EM algorithm: Journal of the Royal Statistical Society, Series B (methodological), v. 39, no. 1, p. 1-38.

Destombes, J., 1962, Stratigraphie et paléogéographie de l'Ordovicien de l'Anti-Atlas (Maroc): un essai de synthèse: Bulletin de la Société géologique de France, v. 4, p. 453-460.

Destombes, J., 1971, L'Ordovicien au Maroc. Essai de synthèse stratigraphique: Mémoire du Bureau de Recherche Géologique Minière, v. 73, p. 237-263.

Destombes, J., 2006, Carte géologique au $200000^{\circ}$ de l'Anti-Atlas marocain. Paléozoïque inférieur: Cambrien moyen et supérieur - Ordovicien - base du Silurien. Sommaire général sur les mémoires explicatifs des cartes géologiques au 1/200 000 de l'Anti-Atlas marocain: Notes et Mémoires du Service géologique du Maroc, v. 515, p. 1-150.

Destombes, J., Hollard, H., and Willefert, S., 1985, Lower Palaeozoic rocks of Morocco, in Holland, C.H., ed., Lower Palaeozoic Rocks of the World. 4. Lower Palaeozoic of North Western - Central Africa: New York, Wiley, p. 91-336.

Felsenstein, J., 2005, PHYLIP (Phylogeny Inference Package) version 3.6: Distributed by the author, Department of Genome Sciences, University of Washington, Seattle.

Frest, T.J, 2005, Ampheristocystis, a Silurian (lower Wenlock) eocrinoid (Echinodermata, Blastozoa) from Indiana: Geological Journal, v. 40, no. 3 , p. 301-329.

Guensburg, T.E., and Sprinkle, J., 2007, Phylogenetic implications of the Protocrinoida: Blastozoans are not ancestral to crinoids: Annales de Paléontologie, v. 93, no. 4, p. 277-290.

Guensburg, T.E, Blake, D.B., Sprinkle, J., and Mooi, R., 2016, Crinoid ancestry without blastozoans: Acta Palaeontologica Polonica, v. 61, no. 2, p. $253-256$.

Gutiérrez-Marco, J.C., and Martin, E., 2016, Biostratigraphy and palaeogeography of Lower Ordovician graptolites from the Fezouata Shale (Moroccan Anti-Atlas): Palaeogeography, Palaeoclimatology, Palaeoecology, v. 460, p. 35-49.

Hammer, Ø., Harper, D.A.T., and Ryan, P.D., 2001, PAST: Paleontological statistics software package for education and data analysis: Palaeontologia Electronica, v. 4, no. 1,9 p.

Honaker, J., King, G., and Blackwell, M., 2011, Amelia II: A program for missing data: Journal of statistical software, v. 45, no. 7, p. 1-47.

Jaekel, O., 1918, Phylogenie und System der Pelmatozoen: Paläontologische Zeitschrift, v. 3, p. 1-128.

Kammer, T.W., Sumrall, C.D., Zamora, S., Ausich, W.I., and Deline, B., 2013 , Oral region homologies in Paleozoic crinoids and other plesiomorphic pentaradial echinoderms: PLoS One, v. 8, no. 11, e77989, p. 1-16.

Lefebvre, B., Sumrall, C.D., Shroat-Lewis, R.A., Reich, M., Webster, G.D., Hunter, A.W., Nardin, E., Rozhnov, S.V., Guensburg, T.E., Touzeau, A., Noailles, F., and Sprinkle, J., 2013, Palaeobiogeography of Ordovician echinoderms, in Harper, D.A.T, and Servais, T., eds., Early Palaeozoic Biogeography and Palaeogeography: Geological Society, London, Memoirs, v. 38, p. 173-198.

Lefebvre, B., El Hariri, K., Lerosey-Aubril, R., Servais, T., and Van Roy, P., 2016a, The Fezouata Shale (Lower Ordovician, Anti-Atlas, Morocco): A historical review: Palaeogeography, Palaeoclimatology, Palaeoecology, v. 460 , p. $7-23$. 
Lefebvre, B., Allaire, N., Guensburg, T.E., Hunter, A.W., Kouraïss, K., Martin, E.L.O., Nardin, E., Noailles, F., Pittet, B., Sumrall, C.D., and Zamora, S., 2016b, Palaeoecological aspects of the diversification of echinoderms in the Lower Ordovician of central Anti-Atlas, Morocco: Palaeogeography, Palaeoclimatology, Palaeoecology, v. 460, p. 97-121.

Lehnert, O., Nowak, H., Sarmiento, G.N., Gutiérrez-Marco, J.C., Akodad, M., and Servais, T., 2016, Conodonts from the Lower Ordovician of MoroccoContributions to age and faunal diversity of the Fezouata Lagerstätte and peri-Gondwana biogeography: Palaeogeography, Palaeoclimatology, Palaeoecology, v. 460, p. 50-61.

Martin, E.L.O., Pittet, B., Gutiérrez-Marco, J.C., Vannier, J., El Hariri, K., Lerosey-Aubril, R., Masrour, M., Nowak, H., Servais, T., Vandenbroucke, T., Van Roy, P., Vaucher, R., and Lefebvre, B., 2016, The Lower Ordovician Fezouata Konservat-Lagerstätte from Morocco: Age, environment and evolutionary perspectives: Gondwana Research, v. 34, p. 274-283.

Mosimann, J.E., 1970, Size allometry: Size and shape variables with characterizations of the lognormal and generalized gamma distributions: Journal of the American Statistical Association, v. 65, p. 930-948.

Nardin, E., 2007, La diversification des blastozoaires (Echinodermata) au Paléozoïque inférieur: Aspects phylogénétiques, paléoécologiques et paléobiogéographiques [Ph.D. thesis]: Dijon, Université de Bourgogne, $532 \mathrm{p}$.

Noailles, F., Lefebvre, B., Guensburg, T.E., Hunter, A.W., Nardin, E., Sumrall, C.D., and Zamora, S., 2010, New echinoderm-Lagerstätten from the Lower Ordovician of central Anti-Atlas (Zagora area, Morocco): A Gondwanan perspective of the Great Ordovician Biodiversification Event, in Reich, M., Reitner, J., Roden, V., and Thuy, B., eds., Echinoderm Research 2010: Göttingen , Universitätsverlag Göttingen, p. 77-78.

Nowak, H., Servais, T., Pittet, B., Vaucher, R., Akodad, M., Gaines, R.R., and Vandenbroucke, T., 2016, Palynomorphs of the Fezouata Formation (Lower Ordovician, Morocco): Age and environmental constraints of the Fezouata Biota: Palaeogeography, Palaeoclimatology, Palaeoecology, v. 460, p. 62-74.

Paul, C.R.C., 1988, The phylogeny of the cystoids, in Paul, C.R.C., and Smith, A.B., eds., Echinoderm Phylogeny and Evolutionary Biology: Oxford, Clarendon Press, p. 199-213.
Smith, A.B., 1988, Patterns of diversification and extinction in Early Palaeozoic echinoderms: Palaeontology, v. 31, p. 799-828.

Sprinkle, J., 1973, Morphology and Evolution of Blastozoan Echinoderms: Cambridge, MA, Museum of Comparative Zoology Harvard University, $284 \mathrm{p}$.

Sprinkle, J., and Guensburg, T.E, 2001, Growing a stalked echinoderm within the extraxial axial theory, in Barker, M., ed., Echinoderms 2000: Proceedings of the 10th International Echinoderm Conference, Dunedin: Lisse, Netherlands, AA Balkema, p. 59-65.

Sumrall, C.D., Sprinkle, J., and Guensburg, T.E., 2001, Comparison of flattened blastozoan echinoderms: Insights from the new Early Ordovician eocrinoid Haimacystis rozhnovi: Journal of Paleontology, v. 75, no. 5, p. $985-992$

Ubaghs, G., 1963, Rhopalocystis destombesi n. g., n. sp., éocrinoïde de l'Ordovicien inférieur (Trémadocien supérieur) du Sud marocain: Notes et Mémoires du Service géologique du Maroc, v. 172, p. 25-45.

Ubaghs, G., 1968, Eocrinoidea, in Moore, R.C., ed., Treatise on Invertebrate Paleontology, Part S. Echinodermata 1., Lawrence, Geological Society of America and University of Kansas Press, p. S495-S565.

Vaucher, R., Martin, E.L.O., Hormière, H., and Pittet, B., 2016, A genetic link between Konzentrat and Konservat Lagerstätten in the Fezouata Formation (Lower Ordovician, Morocco): Palaeogeography, Palaeoclimatology, Palaeoecology, v. 460, p. 24-34

Vaucher, R., Pittet, B., Hormière, H., Martin, E., and Lefebvre, B., 2017, A wave-dominated, tide-modulated model for the Lower Ordovician of the Anti-Atlas, Morocco: Sedimentology, v. 64, no. 3, p. 777-807, doi: $10.1111 /$ sed.12327

Vidal, M., 1996, Le modèle des biofaciès à trilobites: Un test dans l'Ordovicien inférieur de l'Anti-Atlas, Maroc: Compte-Rendus de l'Académie des Sciences, Paris, v. 327, p. 327-333.

Accepted 21 February 2017 